\title{
Effects of PI3K inhibitor NVP-BKM120 on overcoming drug resistance and eliminating cancer stem cells in human breast cancer cells
}

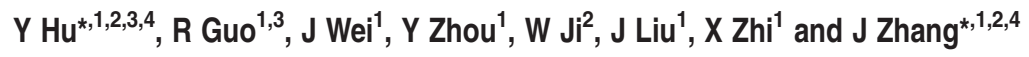

The multidrug resistance (MDR) phenotype often accompanies activation of the phosphatidylinositol 3-kinase (PI3K)/AKT pathway, which renders a survival signal to withstand cytotoxic anticancer drugs and enhances cancer stem cell (CSC) characteristics. As a result, PI3K/AKT-blocking approaches have been proposed as antineoplastic strategies, and inhibitors of PI3K/AKT are currently being trailed clinically in breast cancer patients. However, the effects of PI3K inhibitors on MDR breast cancers have not yet been elucidated. In the present study, the tumorigenic properties of three MDR breast cancer cell lines to a selective inhibitor of PI3K, NVP-BKM120 (BKM120), were assessed. We found that BKM120 showed a significant cytotoxic activity on MDR breast cancer cells both in vitro and in vivo. When doxorubicin (DOX) was combined with BKM120, strong synergistic antiproliferative effect was observed. BKM120 activity induced the blockage of PI3K/AKT signaling and NF- $\kappa$ B expression, which in turn led to activate caspase-3/7 and caspase- 9 and changed the expression of several apoptosis-related gene expression. Furthermore, BKM120 effectively eliminated CSC subpopulation and reduced sphere formation of these drug-resistant cells. Our findings indicate that BKM120 partially overcomes the MDR phenotype in chemoresistant breast cancer through cell apoptosis induction and CSC abolishing, which appears to be mediated by the inhibition of the PI3K/AKT/NF- $\kappa B$ axis. This offers a strong rationale to explore the therapeutic strategy of using BKM120 alone or in combination for chemotherapy-nonresponsive breast cancer patients.

Cell Death and Disease (2015) 6, e2020; doi:10.1038/cddis.2015.363; published online 17 December 2015

Multidrug resistance (MDR) remains a major cause for failure of chemotherapy-based treatment of breast cancer, in which cells become refractory to many structurally and functionally unrelated chemotherapeutic drugs. ${ }^{1}$ Overexpression of P-glycoprotein (P-gp), a member of the ATP-binding cassette (ABC) transporter family encoded by the $m d r-1$ gene, represents one of the principal mechanisms that contribute to the MDR phenotype. ${ }^{2}$ However, many other mechanisms contribute simultaneously to the MDR phenotype, which may affect drug absorption, distribution and metabolism, thus modulating the efficacy of chemotherapeutic agents consequently. ${ }^{3,4}$ Growing evidence supports the notion that a subset of cancer cells, with self-renewal and differentiation features, are the cancer stem cells (CSCs) thought to be responsible for resistance to chemotherapy. ${ }^{5}$ CSCs seem to be protected against chemotherapeutic agents by means of different mechanisms, such as robust proficiency of DNA damage repair, overexpression of $A B C$ transporters, abnormal activation of numerous signaling pathways, including phosphatidylinositol 3-kinase (PI3K)/AKT, Notch, Hedgehog and Wnt pathways. ${ }^{6-8}$ On the other hand, the CSC fraction is probably enriched after chemotherapy, as demonstrated by the increased expression of stemness markers in patients who are receiving primary systematic therapy. ${ }^{9}$

The activation of the PI3K/AKT pathway is frequently implicated in resistance to anticancer therapies. Once activated, AKT can phosphorylate multiple substrates and downstream effectors, such as mTOR family, caspase family, cell cycle protein family and nuclear factor- $k B$ (NF-kB), which contribute collectively to promote cell proliferation, survival, metastasis and chemoresistance. ${ }^{10-12}$ As this signaling cascade has a central role in human breast cancer, development of novel strategies to overcome resistance and eliminate CSC by targeting the PI3K/AKT pathway is apparently warranted. ${ }^{13}$

NVP-BKM120 (referred hereafter as BKM120) is a potent and highly selective pan-class I PI3K inhibitor, which belongs to the 2,6-dimorpholino pyrimidine derivatives. ${ }^{14}$ It selectively inhibits wild type and mutant PI3K p110 a, $\beta, \delta, \gamma$ isoforms and exerts a strong antiproliferative effect to induce apoptosis in several cancers by specifically inhibiting the PI3K/AKT signaling pathway. ${ }^{15-17}$ Phase I clinical trials show that overall BKM120 is well tolerated in several solid tumors, and Phase II clinical trials are ongoing. ${ }^{17}$ Several recent reports also

\footnotetext{
${ }^{1}$ The 3rd Department of Breast Cancer, China Tianjin Breast Cancer Prevention, Treatment and Research Center, Tianjin Medical University Cancer Institute and Hospital, National Clinical Research Center of Cancer, Tianjin, China and ${ }^{2}$ Key Laboratory of Breast Cancer Prevention and Therapy of Ministry of Education, Tianjin, China ${ }^{*}$ Corresponding author: J Zhang or Y Hu, The 3rd Department of Breast Cancer, China Tianjin Breast Cancer Prevention, Treatment and Research Center, Tianjin Medical University Cancer Institute and Hospital, National Clinical Research Center of Cancer, Huan-Hu-Xi Road, Ti Yuan Bei, He xi District, Tianjin 300060, China. Tel: +86 22 23340123 or +86 13702046550; Fax: 862223340123 or +86-022-23537796; E-mail: zhangjin@tjmuch.com or yunhuihu200408@163.com

${ }^{3}$ These authors contributed equally to this work.

${ }^{4}$ Senior corresponding authors contributed equally to this work.

Abbreviations: ALDH, aldehyde dehydrogenase; BKM120, NVP-BKM120; DOX, doxorubicin; MDR, multidrug resistance; NF-кB, Nuclear factor kappa B; P-gp, P-glycoprotein; PI3K, phosphatidylinositol 3-kinase; SC, stem-like cells

Received 01.7.15; revised 30.10.15; accepted 12.11.15; Edited by M Agostini
} 

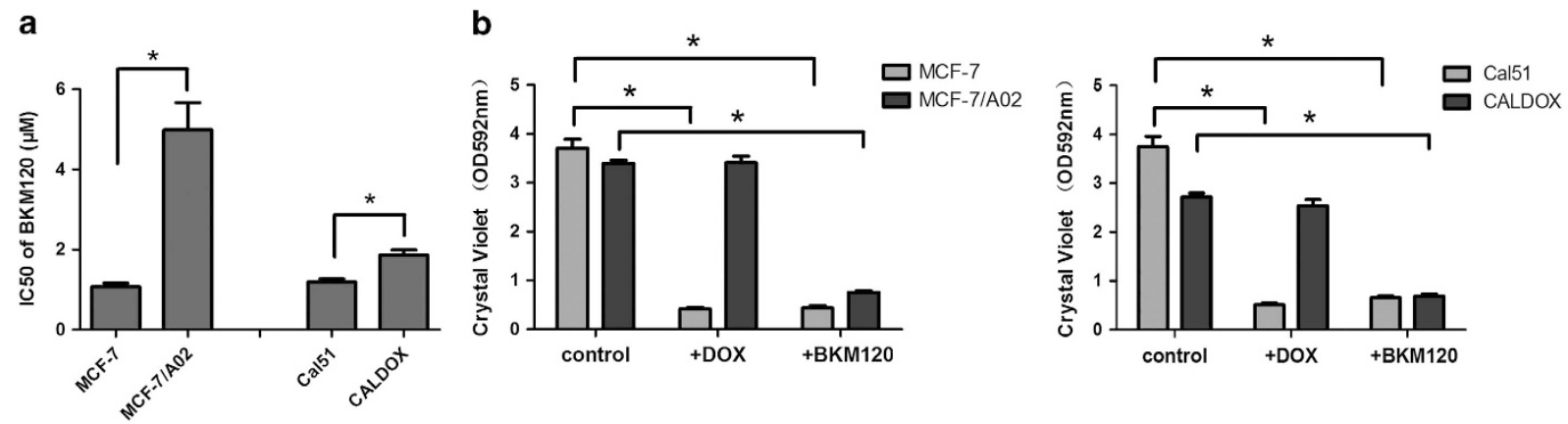

c
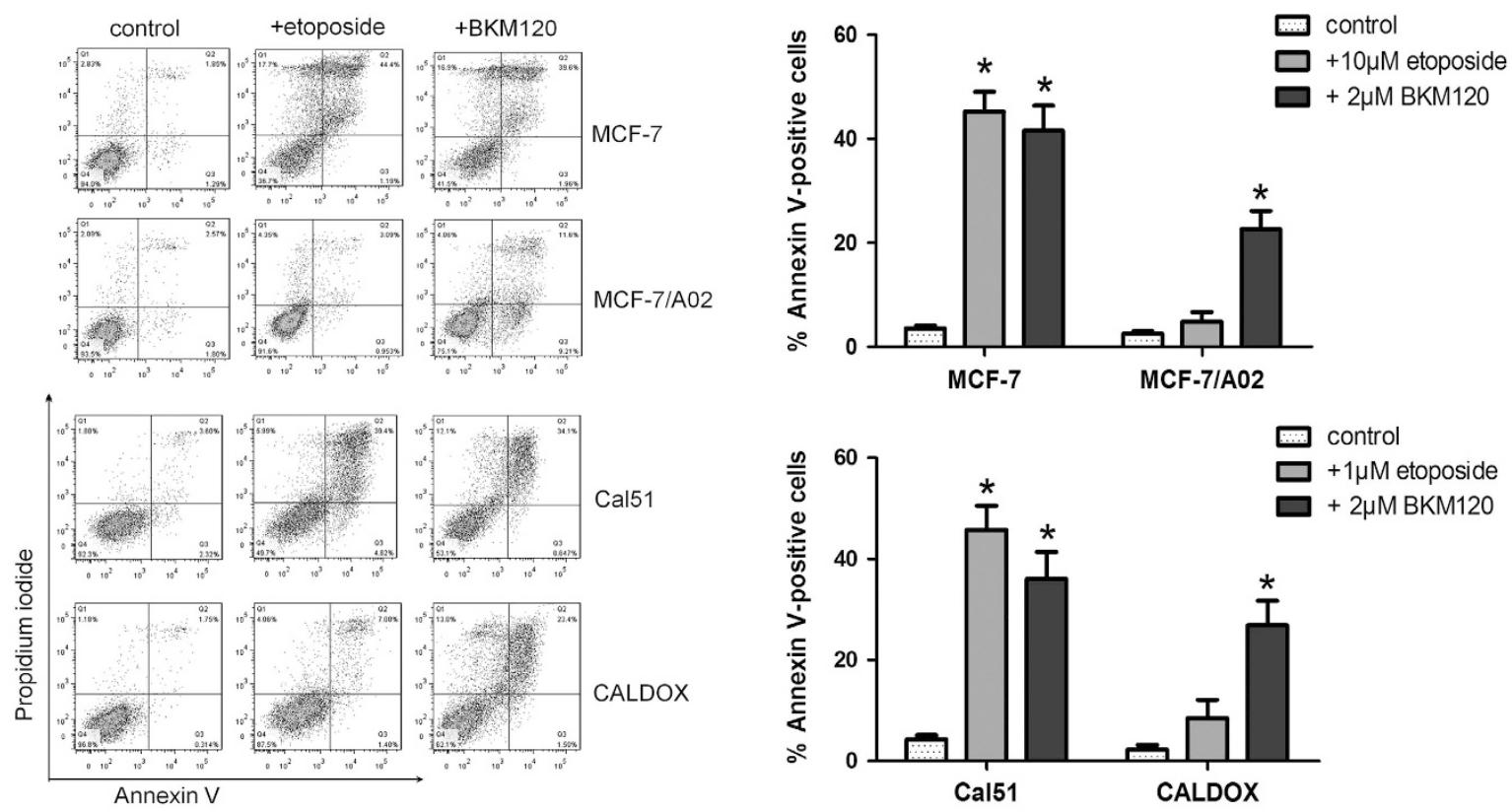

d

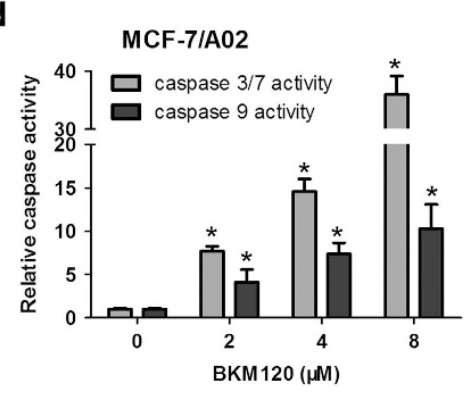

CALDOX

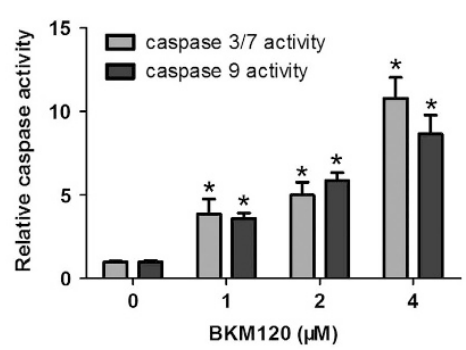

e

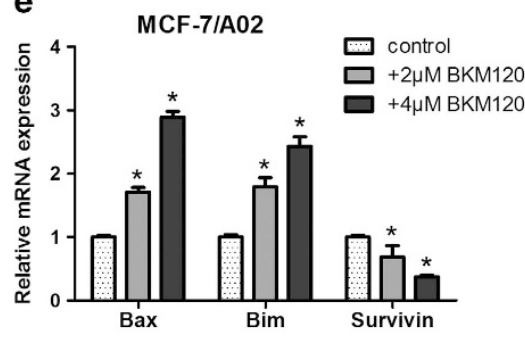

CALDOX

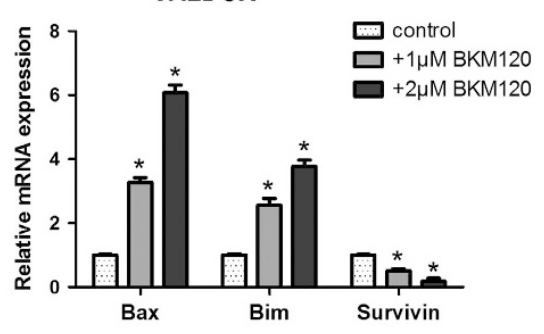

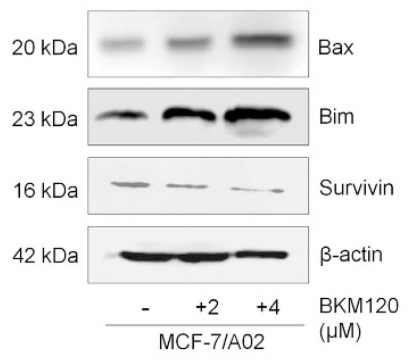

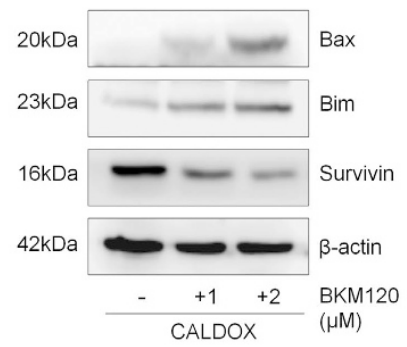


emphasized the enhanced antitumor effects in mouse models when BKM120 was co-treated with inhibitors of other signaling pathways. ${ }^{18-20}$

In this study, we analyzed, for the first time, the efficacy of BKM120 in several MDR breast cancer cell lines with which the MDR phenotype is induced by different molecular mechanisms. BKM120 exerted potent efficacy of apoptosis promoting as well as CSCs eliminating through inhibiting the PI3K/ $\mathrm{AKT} / \mathrm{NF}-\mathrm{KB}$ cascade in vitro and in vivo. In addition, BKM120 synergized with DOX, a common chemotherapeutic agent of breast cancer. Here we demonstrate the potential of BKM120 in overcoming chemotherapy resistance in breast cancer.

\section{Results}

PI3K inhibitor BKM120 shows potent cytotoxicity against both sensitive and MDR breast cancer cell lines. The MDR breast cancer cell lines MCF-7/A02 and CALDOX were derived from chemosensitive cell lines MCF-7 and Cal51, respectively. The MDR phenotype of these derived cell lines was manifested by their cross-resistance to a wide range of structurally and functionally unrelated drugs (Supplementary Tables S1 and S2). BKM120 inhibited growth of chemosensitive and chemoresistant breast cancer cells in a dosedependent manner (Supplementary Figure S1A); the IC50 assay results revealed that two drug-resistant cell lines exhibited only 4.64- and 1.56-fold resistance to BKM120, respectively, compared with their parental chemosensitive counterparts (Figure 1a). Similar results were also observed in another pair of breast cancer cell lines, the relatively sensitive MTMEC cell line and its DOX-resistant derivative MD60 cell line (Supplementary Figures S2A and B). BKM120 appeared to be more effective in eliminating drug-resistant cells than chemotherapeutic drugs. To further evaluate the cytotoxic effect of BKM120 on chemosensitive and chemoresistant breast cancer cells, the cells were treated with either DOX or BKM120. Crystal violet staining was used to determine the cell mass 1 week after treatment. As expected, the chemoresistant cells robustly defied DOX, whereas the same concentration of DOX eradicated most drug-naive cells. However, BKM120 significantly decreased the capacity of MDR cells to survive after 1-week treatment (reduction ranging from 72.4 to $77.7 \%$, Figure $1 \mathrm{~b}$ and Supplementary Figure S1B). These results demonstrate that BKM120 is a potent cytotoxic agent to MDR breast cancer cells.

BKM120 promotes cell apoptosis, induces caspase activity and modulates apoptosis-related genes. Next, we asked whether the cytotoxic effect of BKM120 on chemoresistant breast cancer cells is mediated by promoting cell apoptosis. As DOX can be excited at $488 \mathrm{~nm}$ by blue excitation laser, with emission at $\sim 595 \mathrm{~nm},{ }^{21}$ thereby interfering with the results of the Annexin V/propidium iodide (PI) staining assay, we used etoposide, another widely used drug known to induce cell apoptosis ${ }^{22,23}$ as a positive control. As illustrated in Figure 1c, $10 \mu \mathrm{M}$ etoposide showed similar apoptosis-inducing effect as $2 \mu \mathrm{M}$ BKM120 did in MCF-7 cells, but failed to do so in MCF-7/A02 cells. After $2-\mu \mathrm{M}$ BKM120 treatment, the percentage of apoptotic MCF-7/A02 cells increased remarkably. A similar effect of BKM120 treatment on promoting apoptosis was also observed in CALDOX cells. In accordance with the Annexin V/PI analysis, BKM120 strongly induced caspase-3/7 and caspase- 9 activities in MCF-7/A02 and CALDOX cells, respectively (Figure 1d), which was also confirmed in MD60 cells (Supplementary Figure S2C). As Supplementary Figure S1D shows, the pancaspase inhibitor z-VAD-fmk was able to abrogate Caspase-3/7 and Caspase 9 activities mediated by BKM120 intensively in MCF-7/A02 and CALDOX cells, confirming the specificity of the observed effects. Cells were untreated or pretreated with z-VAD-fmk for $4 \mathrm{~h}$, followed by treatment with BKM120, and were subsequently analyzed for cell viability by MTT assay and cell apoptosis by Annexin V/PI staining assays. z-VAD-fmk reduced the percentage of Annexin V-positive cells (both PI low, early apoptotic and PI high, late apoptotic/necrotic) upon BKM120 treatment. In addition, there was almost a 2.6-fold shift in the $I_{50}$ for MCF-7/A02 cells and a 3.9-fold shift in the IC50 for CALDOX. These data demonstrate the specific induction of cell death by BKM120 through the activation of the apoptotic cascade (Supplementary Figure S1E and F). As the induction of apoptotic cell death could be partly due to alteration of apoptosis-related genes, we evaluated the mRNA levels of several survival genes, including $B c l-2, B c l-x l$, Survivin and $M c l-1$, as well as apoptotic genes, Bim and Bax. Reverse transcription quantitative real-time-PCR (RT-qPCR) and western blot results revealed that BKM120 repressed pro-survival gene Survivin expression and upregulated pro-apoptotic genes Bim and Bax expression in MDR cells (Figure 1e), although the expressions of $B c /-2, B C l-x l$ and $\mathrm{Mcl}-1$ were not changed (Supplementary Figure S1C).

To further confirm that promoting effect of BKM120 on apoptosis is specifically mediated by PI3K/AKT inhibition, chemoresistant breast cancer cells were treated with LY294002, another well-characterized selective PI3K/Akt inhibitor. Similar to BKM120, the $\mathrm{IC}_{50}$ values of LY294002 in MCF-7/A02 and CALDOX cells are only 7.38 and 2.18 times greater than those in MCF-7 and Cal51 cells, respectively (Figure 2a). LY294002 significantly induced cell apoptosis and

\footnotetext{
Figure 1 BKM120 is cytotoxic to MDR breast cancer cells by activating apoptosis. (a) IC $\mathrm{F}_{50}$ values of BKM120 of two pairs of human breast cancer cell lines and their MDR sublines. (b) Cells were treated with doxorubicin ( $3 \mu \mathrm{M}$ for MCF-7 and MCF-7/A02, $0.2 \mu \mathrm{M}$ for Cal51 and CALDOX) and BKM120 (2 $\mu \mathrm{M}$ for all cell lines) for 7 days, and the cells were stained with crystal violet. Dye was solubilized and the optical density at $592 \mathrm{~nm}$ was measured. (c) Cells were treated with etoposide (10 $\mu \mathrm{M}$ for MCF-7 and MCF-7/A02, $1 \mu \mathrm{M}$ for Cal51 and CALDOX) and BKM120 (2 $\mu \mathrm{M}$ for all cell lines) for $48 \mathrm{~h}$. Annexin V/PI staining was detected with flow cytometry. Representative plots of three independent experiments are shown. Quantitative data show the average percentage of annexin V-positive cells (both in early apoptosis, lower right quadrant and late apoptosis, upper right quadrant) of three independent experiments (right panel). (d) Caspase-3/7 and caspase- 9 activities in MCF-7/A02 (upper histograms) and CALDOX cells (lower histograms) after BKM120 treatment. (e) Fold changes of Bax, Bim and Survivin expression levels in MCF-7/A02 and CALDOX cells determined using RT-qPCR (left panel) and western blot (right panel) after BKM120 treatment at various concentrations for $48 \mathrm{~h}$. Numerical data are presented as mean \pm S.D. of three independent experiments. ${ }^{*} P<0.05$
} 

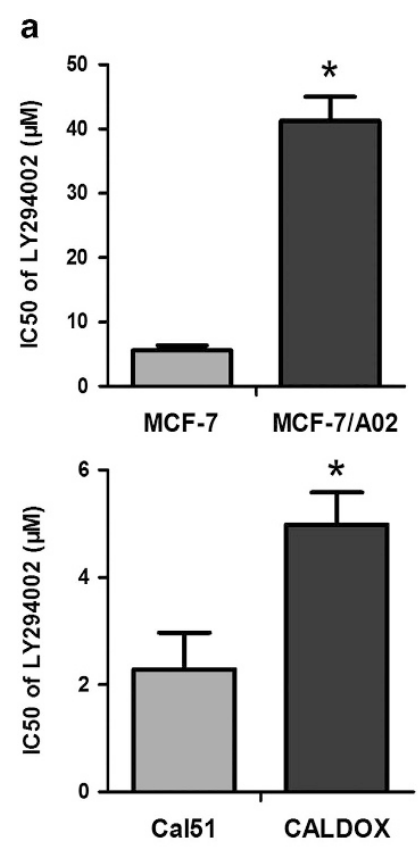

C

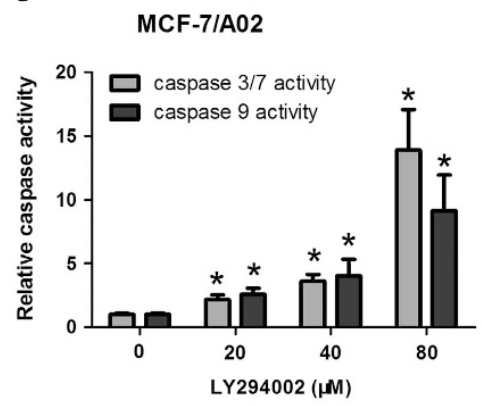

CALDOX

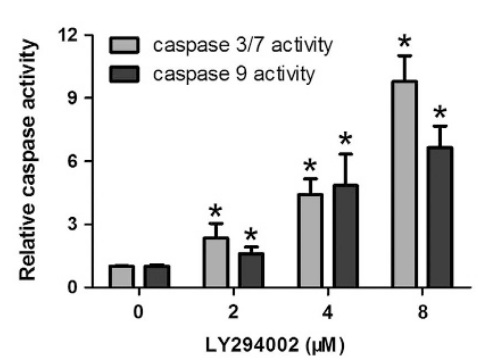

b
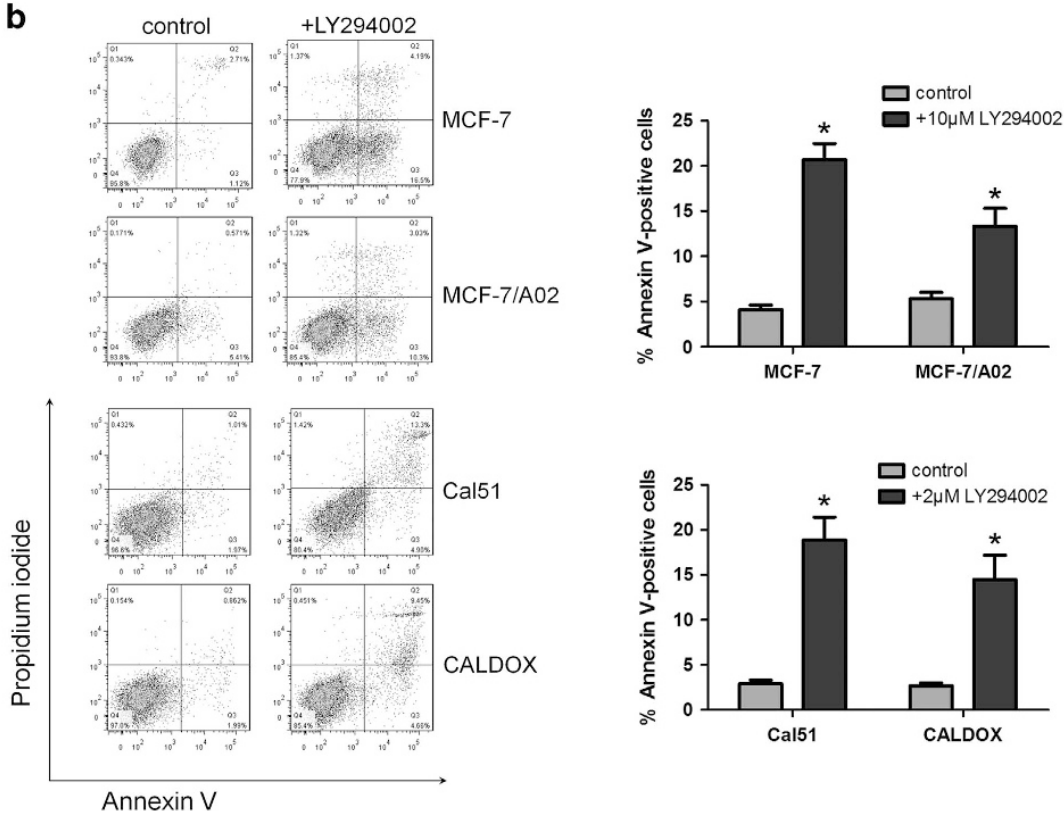

d
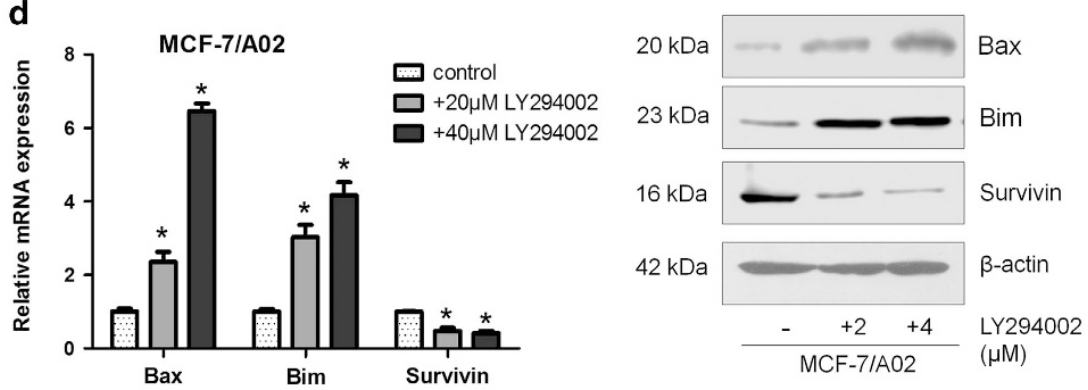

CALDOX
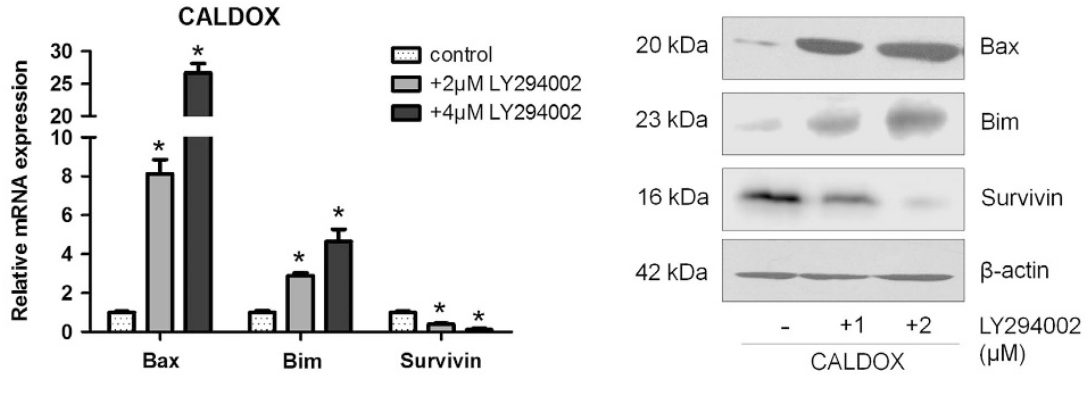

Figure 2 Blocking the PI3K/Akt pathway by LY294002 induces apoptosis in MDR breast cancer cells. (a) IC 50 value of LY294002 in MCF-7 and MCF-7/A02 (upper panel), Cal51 and CALDOX (lower panel). (b) Cells were treated with LY294002 (10 $\mu \mathrm{M}$ for MCF-7 and MCF-7/A02, $2 \mu \mathrm{M}$ for Cal51 and CALDOX) for $48 \mathrm{~h}$. Annexin V/PI staining was detected using flow cytometry. Representative plots of three independent experiments are shown. Quantitative data show the average percentage of annexin V-positive cells (both in early apoptosis, lower right quadrant and late apoptosis, upper right quadrant) of three independent experiments (right panel). (c) Caspase-3/7 and caspase-9 activities of MCF-7/A02 (upper histograms) and CALDOX (lower histograms) after LY294002 treatment. (d) Fold changes of Bax, Bim and Survivin expression levels determined using RT-qPCR (left panel) and western blot (right panel) in MCF-7/A02 and CALDOX after LY294002 treatment with various concentrations for $48 \mathrm{~h}$. Numerical data are presented as mean \pm S.D. of three independent replicates. ${ }^{*} P<0.05$

activated caspases in MCF-7/A02 and CALDOX cells (Figure $2 \mathrm{~b}$ and c). In addition, LY294002 treatment also enhanced Bax and Bim expression and reduced Survivin mRNA and protein levels (Figure 2d). Thus, attenuating PI3K/AKT signaling appears to be an important pathway to induce chemoresistant breast cancer cell apoptosis.
BKM120 induces cytotoxicity through blocking the PI3KJ AKT/NF- $\mathbf{B}$ signaling pathway. The PI3K/AKT signaling pathway is frequently dysregulated in human cancer and has been implicated in the development of resistance to standard anticancer therapies. ${ }^{24-26}$ It is known that chemoresistant MCF-7/A02 cells are mainly mediated by increased P-gp 
a

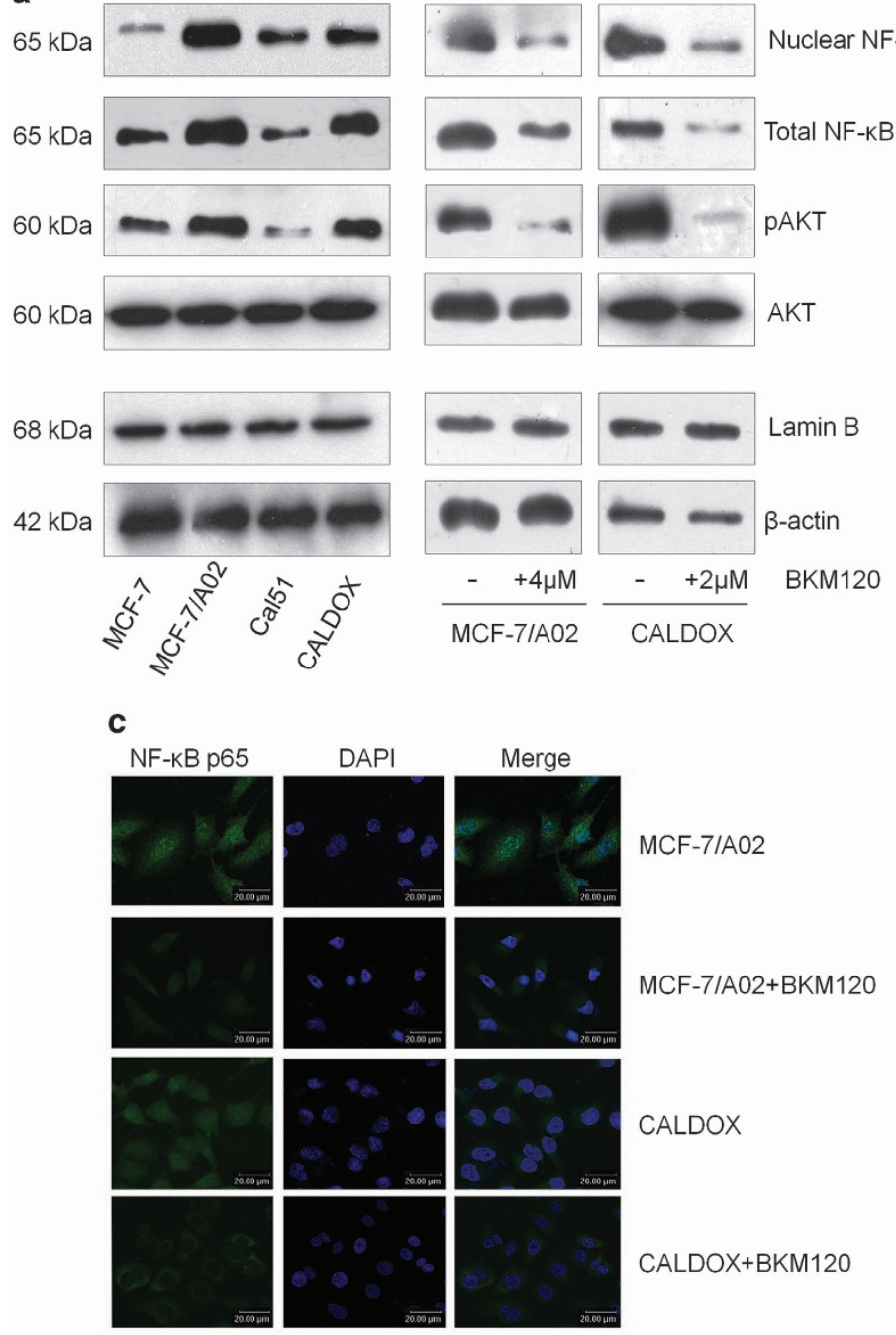

b

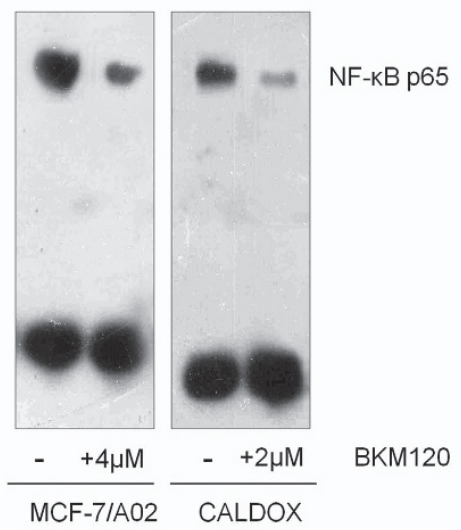

d

f
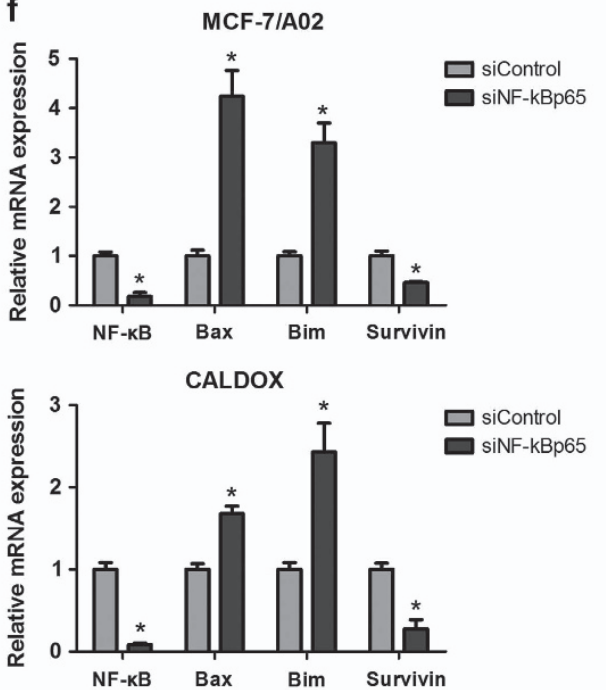

$65 \mathrm{kDa}$

$65 \mathrm{kDa}$

60 kDa

60 kDa
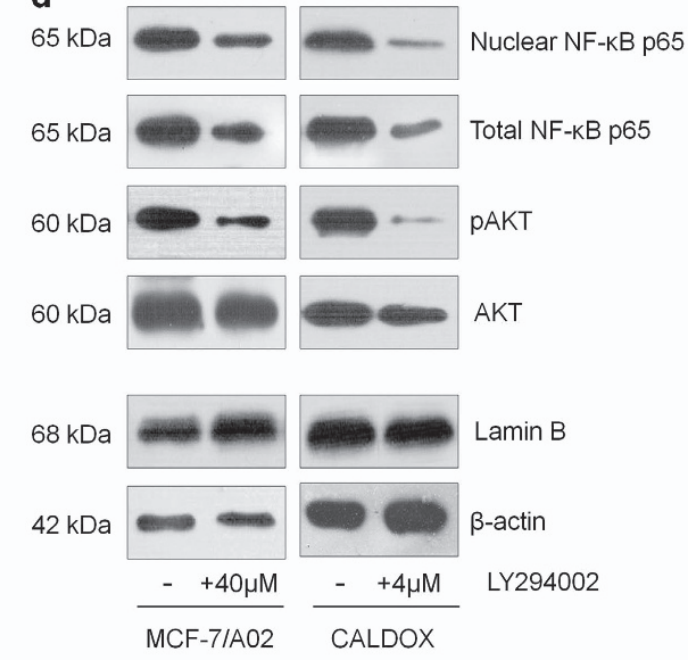

KT e
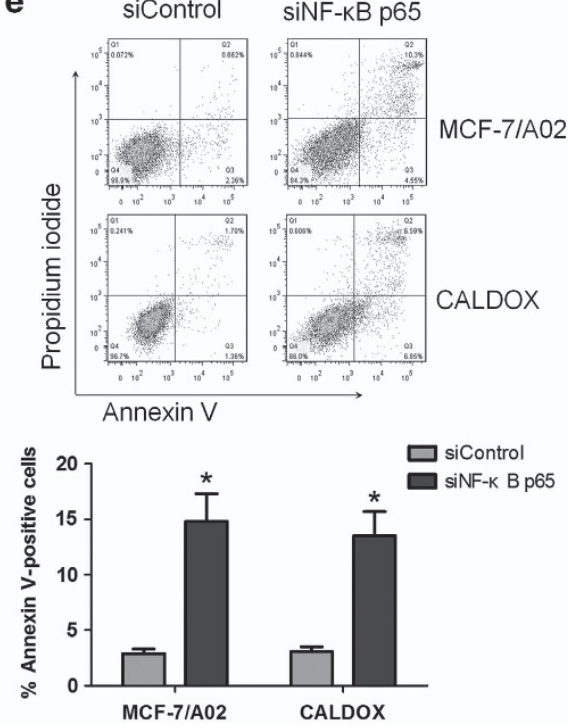
expression, whereas the chemoresistance in CALDOX cells is due to the loss of expression of TOP2A, rather than overexpression of membrane transporters. ${ }^{27,28}$ Although the leading causes of MDR phenotype are quite different, the $\mathrm{PI}$ IK/AKT signaling cascade in these two MDR cell lines was found to be overactivated compared with their parental cell lines (Figure 3a). Our data indicated that induction of cell apoptosis by BKM120 in both MDR cancer cell lines was associated with a significant reduction in AKT phosphorylation, suggesting a decrease in PI3K activity (Figure 3a).

As PI3K/AKT signaling has a pivotal role through regulating diverse downstream effectors, we sought to determine the potential downstream effector that involves in BKM120induced apoptosis in MDR cells. The crosstalk between NF- $K B$ activity and PI3K/AKT pathway has been shown in various cancers, and constitutive activation of $\mathrm{NF}-\kappa \mathrm{B}$ induced by the PI3K/AKT pathway may have a major role in the development of chemoresistance. ${ }^{29,30}$ Our western blot results revealed that MDR cells contained higher NF- $\kappa \mathrm{B}$ p65 protein levels in whole-cell extracts as well as in the nuclear compartment, where NF- $\kappa \mathrm{B}$ p65 exerts its transcriptional activity (Figure 3a). Therefore, we speculated that BKM120 exerts its apoptotic induction through downregulating the $\mathrm{PI} 3 \mathrm{~K} / \mathrm{AKT} / \mathrm{NF}-K \mathrm{~B}$ cascade in MDR breast cancer cells. To address this issue, we examined mRNA and protein levels (Figure $3 a$ and Supplementary Figure S3A), cellular localization (Figure $3 a$ and $c$ ) and DNA-binding activity (Figure $3 b$ ) of the NF- $K$ B p65 subunit in MCF-7/A02 and CALDOX cells. The results showed that BKM120 significantly decreased NF- $k B$ p65 expression and its DNA-binding activity (Figure $3 a-c$ and Supplementary Figure S3A). LY294002 also displayed a suppressive effect on NF-KB p65 expression similar to what was observed in BKM120 treatment in these MDR cells (Figure 3d and Supplementary Figure S3B).

To ascertain whether the downregulation of NF- $K B$ activity influenced apoptosis-related gene expression, we used a small interfering RNA (siRNA) approach to knockdown NF- $\kappa$ B p65. Figure $3 e$ and $f$ showed that NF-kB p65 siRNA transfection significantly reduced $\mathrm{NF}-\kappa \mathrm{B}$ p65 and Survivin mRNA levels, increased Bim and Bax expression and concomitantly led to cell apoptosis when compared with scramble siRNA-transfected cells. Taken together, these results demonstrate that $\mathrm{PI} 3 \mathrm{~K} / \mathrm{AKT}$ inhibitor BKM120 induces MDR breast cancer cell apoptosis through suppressing NF- $K B$ activity.

BKM120 eliminates stem cell subpopulation of MDR breast cancer cells. Drug-resistant cells have been proposed to arise from the selection of a small population of cells with stem-like properties. ${ }^{5}$ BKM120 has been shown to have robust anticancer properties in MDR breast cancer cells; therefore, we then asked whether BKM120 could also eliminate stem cell population of MDR cells. First, we tested the effect of BKM120 on the proportion of stem-like cell (SC) population in chemoresistant breast cancer total cells (TCs). We analyzed the expression of CD44 and CD24, two cellsurface markers whose expression in the CD $44^{\text {high }} / \mathrm{CD} 24^{\text {low }}$ configuration is associated with breast SCs. ${ }^{31}$ Emergence of MDR was indeed accompanied by an increase in the percentage of CD $44^{\text {high }} / \mathrm{CD} 24^{\text {low }}$ cells (Figure $4 a$ ). As expected, the percentage of CD44 $4^{\text {high }} / \mathrm{CD} 24^{\text {low }}$ cells was reduced in MCF-7/A02 and CALDOX cells after BKM120 treatment in a range of doses lower than $\mathrm{IC}_{50}$ (Figure $4 \mathrm{a}$ ). We then analyzed aldehyde dehydrogenase (ALDH) activity, another important marker of SCs. ${ }^{32}$ Comparing MCF-7 and Cal51 cells, both MCF-7/A02 and CALDOX cell lines were composed of a much higher population of cells exhibiting ALDH activity (Figure 4b), and the ALDH activity in these MDR cell lines were remarkably inhibited after exposure to BKM120 in the doses lower than $I_{50}$ (Figure $4 b$ ). Similar effect of BKM120 was observed in MD60 cells (Supplementary Figure S2E).

Breast SCs exhibit other stem-like properties, including the ability to survive and grow as spheres or colonies under certain conditions, such as low attachment plates and soft agar medium. ${ }^{33}$ First, we observed that MCF-7/A02 and CALDOX cells indeed formed higher numbers of spheres and clones than their parental cell lines (Figure 4c and d). Second, BKM120 eliminated MCF-7/A02 and CALDOX cells' sphereforming efficacy (SFE), as well as the ability to produce colonies (Figure 4c and d and Supplementary Figure S4A and B). Third, primary mammospheres from each cell line were enzymatically dispersed to single cells and assayed for their ability to form secondary mammospheres. BKM120 treatment maintained SFE inhibition in the second passage of both MCF-7/A02 and CALDOX cell lines (Figure 4c).

As the mammosphere technique has been proven for enriching the highly tumorigenic SCs, ${ }^{34,35}$ the mammosphere cells (MCs) from MCF-7/A02 and CALDOX cells were obtained through sphere-forming assay as mentioned above. Comparing with TCs, MC has more CD $44^{\text {high }} / \mathrm{CD} 24^{\text {low }}$ subpopulation and $\mathrm{ALDH} 1^{\text {high }}$ subpopulation analyzed using flow cytometry (Supplementary Figure S5). As the MTT assay results show, DOX and etoposide were more cytotoxic in chemoresistant TCs than in their MCs. MCF-7/A02 and CALDOX MCs exhibited 68- and 47-fold greater resistance to DOX than MCF-7/A02 and CALDOX TCs, respectively (Table 1). In addition, MCF-7/A02 and CALDOX MCs

\footnotetext{
Figure 3 The PI3K/AKT pathway inhibitor induces apoptosis through suppressing NF- $K$ B activity. (a) Western blots show BKM120 downregulating pAKT, nuclear NF- $\kappa B$ p65 and total NF- $\kappa \mathrm{B}$ p65 in MDR and their parental cells. $\beta$-actin was used as a loading control for pAKT, AKT and total NF- $\kappa \mathrm{B}$ p65. Lamin B was used as a loading control for nuclear NF- $\kappa \mathrm{B}$ p65. (b) EMSA results show that BKM120 treatments ( $4 \mu \mathrm{M}$ for MCF-7/A02 and $2 \mu \mathrm{M}$ for CALDOX) decreased NF- $\kappa$ B DNA-binding activity in MDR cells. (c) Immunofluorescence staining of NF- $\kappa B$ p65 in MDR cells treated with or without BKM120 (4 $\mu \mathrm{M}$ for MCF-7/A02 and $2 \mu \mathrm{M}$ for CALDOX) for $48 \mathrm{~h}$. (d) Western blots show LY294002 treatments (40 $\mu \mathrm{M}$ for MCF-7/A02 and $4 \mu \mathrm{M}$ for CALDOX) downregulating pAKT, nuclear NF- $\kappa$ B p 65 and total NF- $\kappa$ B p65 in MDR cells. (e) MCF-7/A02 and CALDOX cells were transiently transfected with NF- $k$ B p65 siRNA (siNF- $k B$ p65) or scrambled siRNA (siControl). Three days after transfection, cells were stained with Annexin V/PI and cell death was quantified using flow cytometry. Representative plots of three independent experiments are shown. Quantitative data show the average percentage of annexin V-positive cells (both in early apoptosis, lower right quadrant, and late apoptosis, upper right quadrant) of three independent experiments (lower panel). (f) Fold changes of NF-kB p65, Bax, Bim and Survivin mRNA levels detected using RT-qPCR in MDR cells after NF- $k B$ p65 siRNA transfection for $72 \mathrm{~h}$. Numerical data are presented as mean \pm S.D. of three independent replicates. ${ }^{*} P<0.05$
} 
a
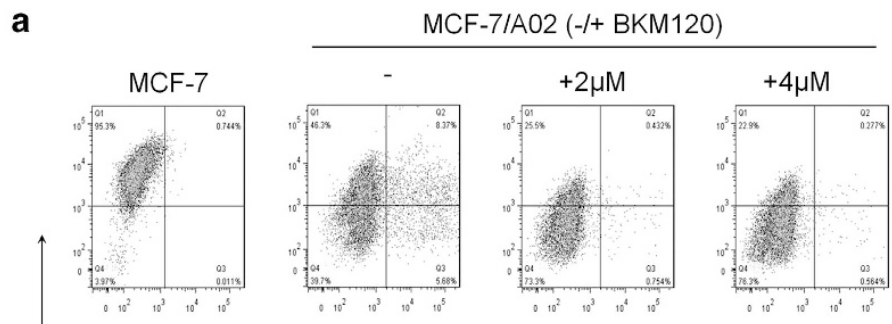

CALDOX (-/+ BKM120)
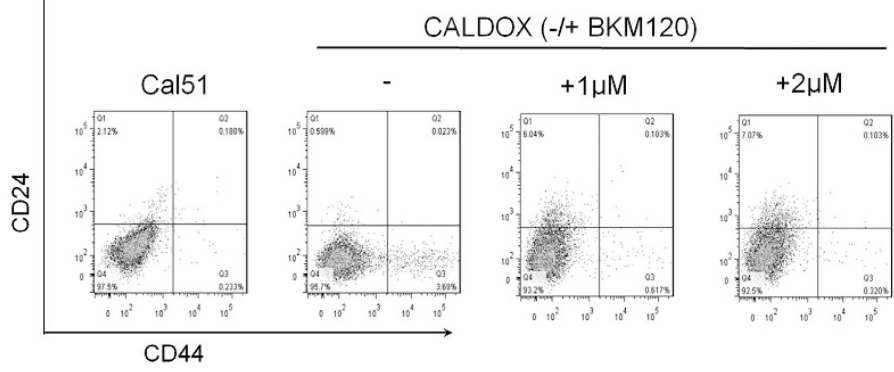

b
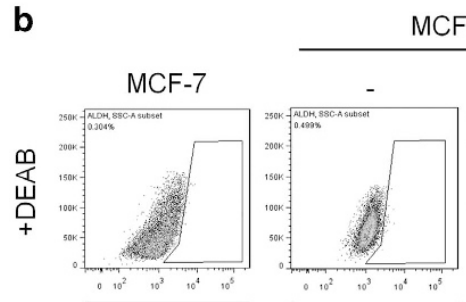

MCF-7/A02 (-/+ BKM120)
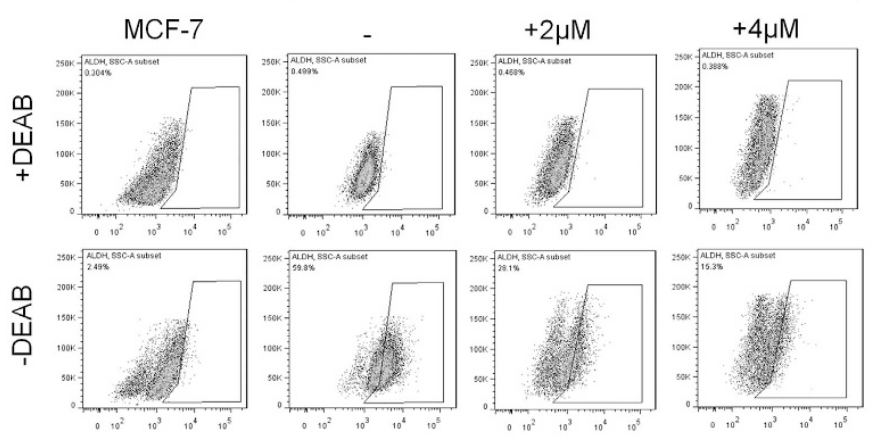

CALDOX (-/+ BKM120)
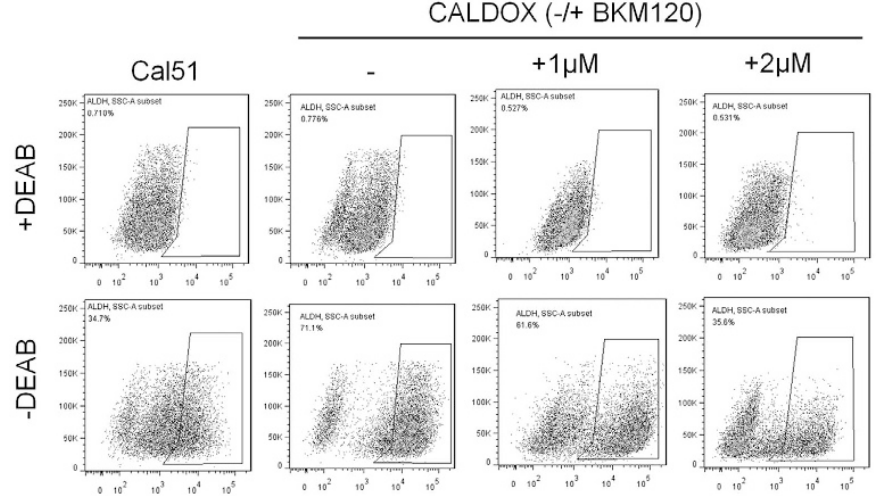
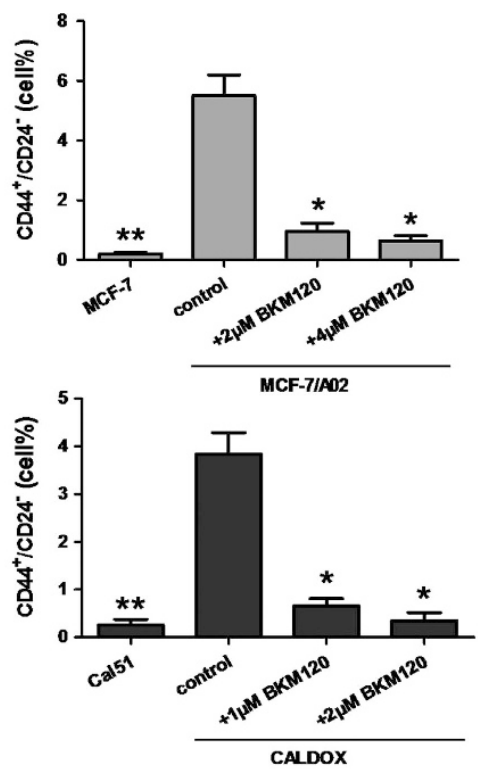

Figure 4 The inhibitory effects of BKM120 on SC in MDR breast cancer cells. (a) Flow cytometry plots for CD44 and CD24 of MDR and their parental cells. Cells in Q3 $\left(C D 44^{\text {high }} \mathrm{CD} 24^{\text {low }}\right)$ are associated with SC subpopulation. Quantitative data show the average percentage of $\mathrm{CD} 44^{\text {high }} \mathrm{CD} 24^{\text {low }}$ cells (right panel). (b) Flow cytometry analysis of ALDH activity. Cells treated with or without BKM120 for $48 \mathrm{~h}$ were assayed with an Aldefluor assay kit in the presence and absence of the ALDH inhibitor diethylaminobenzaldehyde (DEAB). Gating in the control was set up to a maximum of $1 \%$ of cells. Representative plots of at least three independent experiments are shown. Quantitative data show the average percentage of ALDH high cells (right panel). (c) Primary and secondary mammosphere-forming efficacies of MDR and their parental cells. SFE was calculated as the number of spheres formed in 10 days divided by the original number of single cells seeded and expressed as percentage. Bars represent the mean percentage of mammospheres. (d) Anchorage independence was determined by the formation of clones in soft agar cultured for 3 weeks. Histogram data represent the average number of colonies counted in randomly chosen five visual fields under the microscope (magnification $\times 40$ ). (e) Dose-response curves were used to calculate the $\mathrm{IC}_{50}$ of BKM120 for MCs of MCF-7/A02 cells (upper) and CALDOX cells (lower). (f) Caspase-3/7 and caspase-9 activities of MCF-7/A02-MC (upper histograms) and CALDOX-MC (lower histograms) after BKM120 treatment. Numerical data are presented as mean \pm S.D. of three independent experiments. ${ }^{\star} P<0.05,{ }^{* \star} P<0.01$ 


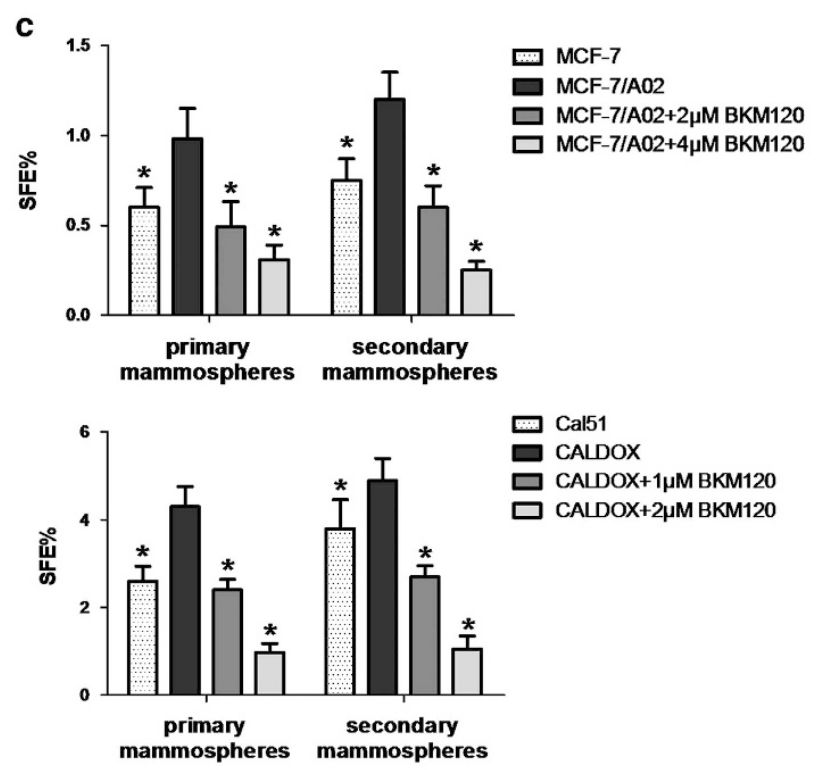

d
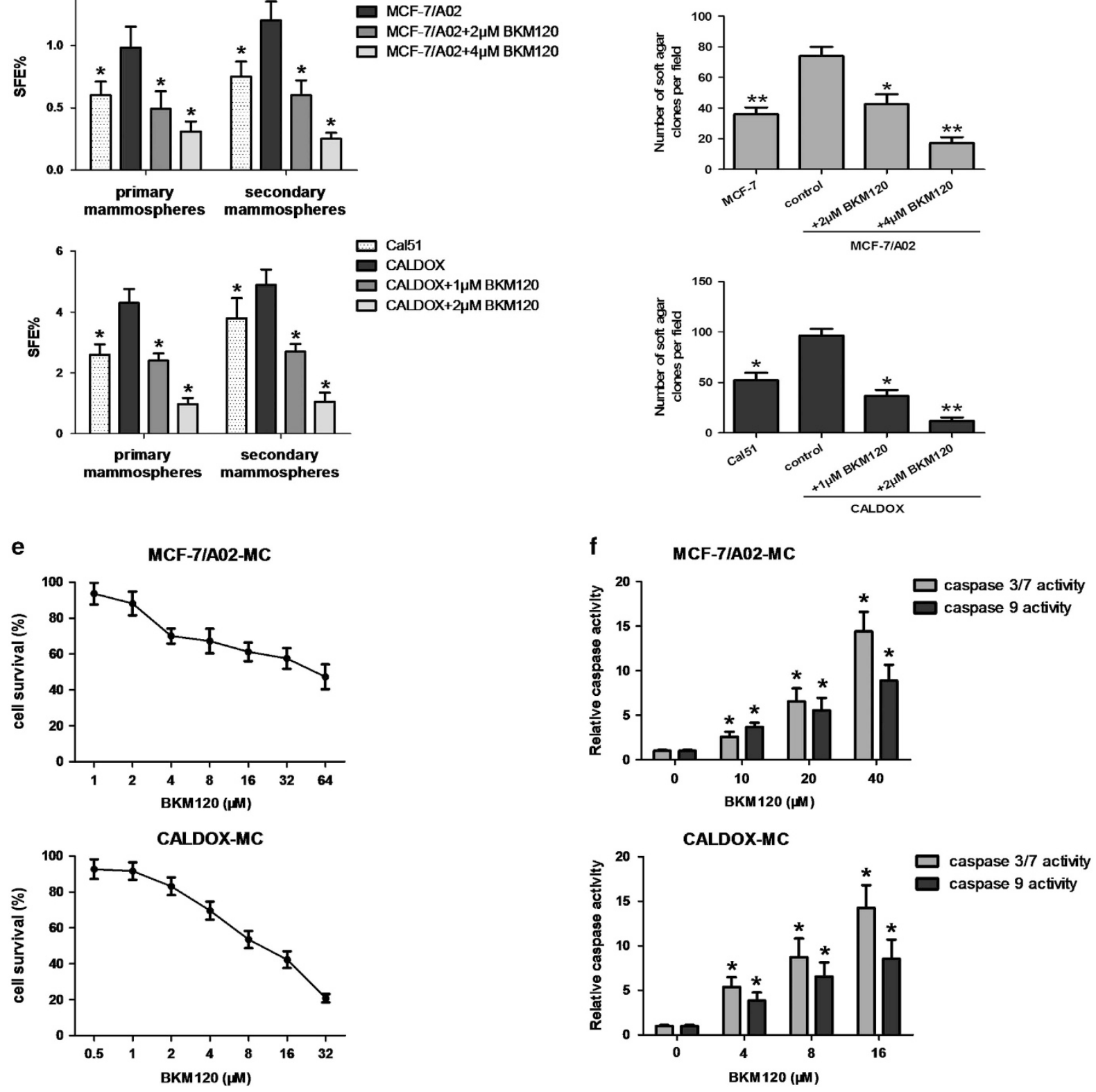

Figure 4 Countinued.

exhibited 42- and 18-fold greater resistance to etoposide than MCF-7/A02 and CALDOX TCs, respectively (Table 1). BKM120 also displayed a cytotoxic effect on these MCs in a dose-dependent manner and significantly induced caspase activities (Figure 4e and f). Compared with the TCs, the resistance of MCs to BKM120 only ranged from 4.61- to 5.73-folds (Table 1), which indicated that BKM120 could kill MCs more efficiently than DOX and etoposide.

To ascertain that blockage of the PI3K/AKT/NF-kB cascade was functionally important for BKM120-induced stemness reduction in MDR cell lines, we used LY294002 and NF- $k$ B p65 siRNA to specifically inhibit PI3K/AKT activity and NF- $K B$ p65 expression. Figure 5 confirmed that abolishing PI3K/AKT signaling or NF-kB p65 silencing was sufficient to decrease
$\mathrm{ALDH}^{\text {high }}$ population as well as SFE in MCF-7/A02 and CALDOX cells.

BKM120 is synergistic with chemotherapeutic agents in MDR breast cancer cells. Alterations in the PI3K/AKT signaling pathway have been shown to track consistently with therapy-induced resistance in breast cancer patients, including endocrine-based therapy, chemotherapy and HER2-targeted therapy. ${ }^{36-38}$ Recent studies demonstrate that targeting the PI3K/AKT pathway in combination with trastuzumab or tamoxifen is beneficial in trastuzumabresistant breast cancer or endocrine therapy-resistant breast cancer. ${ }^{38,39}$ Hence, we further investigated whether BKM120 could synergize with chemotherapeutic agents commonly 
Table 1 Mammosphere cells of MCF-7/A02 and CALDOX sensitivity to different drugs

\begin{tabular}{|c|c|c|c|}
\hline \multirow[t]{2}{*}{ Drug $(\mu \mathrm{M})$} & \multicolumn{2}{|c|}{$I_{50}$ of MCF-7/AO2 } & \multirow{2}{*}{$\begin{array}{l}\text { Mammosphere-cell } \\
\text { resistance ratio }\end{array}$} \\
\hline & $\begin{array}{l}\text { Total } \\
\text { cells }\end{array}$ & $\begin{array}{l}\text { Mammosphere } \\
\text { cells }\end{array}$ & \\
\hline Doxorubicin & 128.3 & 8827 & 68.80 \\
\hline Etoposide & 206.8 & 8747 & 42.30 \\
\hline BKM120 & 5.6 & 32.1 & 5.73 \\
\hline \multirow[t]{2}{*}{ Drug $(\mu \mathrm{M})$} & \multicolumn{2}{|c|}{$I_{50}$ of CALDOX } & Mammosphere-cell \\
\hline & $\begin{array}{l}\text { Total } \\
\text { cells }\end{array}$ & $\begin{array}{c}\text { Mammosphere } \\
\text { cells }\end{array}$ & \\
\hline Doxorubicin & 5.73 & 272.7 & 47.59 \\
\hline Etoposide & 26.8 & 487.8 & 18.20 \\
\hline BKM120 & 1.8 & 8.3 & 4.61 \\
\hline
\end{tabular}

used in breast cancer therapy regimens. For this purpose, MCF-7/A02 and CALDOX cells were treated with increasing concentrations of DOX/etoposide, either alone or in combination with BKM120 at fixed ratios (DOX/BKM120, 5:1 for MCF-7/A02; etoposide/BKM120, 15:1 for MCF-7/A02; DOX/ BKM120, 1.25:1 for CALDOX; and etoposide/BKM120, 25:1 for CALDOX). As shown in Table 2, the combination index (CI) values ranged from 0.1 to 0.6 , indicating that DOX or etoposide and BKM120 used in combination acted synergistically in MCF-7/A02 and CALDOX cells.

As P-gp (encoded by $m d r-1$ ) overexpression is the most crucial mechanism that contributes to MDR phenotype in many cancer cells including MCF-7/A02, we examined whether BKM120 modulates P-gp expression. RT-qPCR results showed that, although administration of $8 \mu \mathrm{M}$ BKM120 caused almost $50 \%$ of the cells undergoing apoptosis, the mRNA levels of $m d r-1$ in MCF-7/A02 remained constantly elevated (Supplementary Figure S6A). Furthermore, the Rhodamine 123 retention in the cells as detected with flow cytometry demonstrated that intracellular Rhodamine 123 levels were not enhanced in MCF-7/A02 cells after BKM120 treatment (Supplementary Figure S6C). The MDR phenotype of CALDOX did not involve drug transporters, as resistant cell-accumulated Rhodamine 123 was comparable to the parental cells (Supplementary Figure S6C). It has been recently reported that chemoresistance of CALDOX is partially caused by the downregulation of TOP2A. ${ }^{28}$ In accordance with the previous finding, RT-qPCR analysis showed that TOP2A mRNA levels were significantly lower in CALDOX cells than their parental cells. However, BKM120 did not alter TOP2A expression (Supplementary Figure S6B). These findings suggest that the increase in MDR breast cancer cell sensitivity to chemotherapeutic agents by BKM120 is independent of P-gp and TOP2A expression.

Effect of BKM120 on xenograft tumor growth of MCF-7I A02 and CALDOX cells in nude mice. The significant antitumor activity of BKM120 on chemoresistant breast cancer cells in vitro led us to investigate whether its antitumor efficacy would be maintained in vivo. MCF-7/A02 and CALDOX cells were injected into the mammary fat pad of female nude mice. On day 14 after injection, mice were randomly divided into four groups with equal number of mice. Each group was treated with BKM120, DOX, BKM120 plus DOX or vehicle control, respectively. As expected, the tumor continued to grow in DOX-treated groups in both xenograft models indicating DOX resistance, whereas BKM120 alone substantially curtailed tumor progression in both xenograft models relative to vehicle control and DOX-treated groups (Figure 6a and b). Moreover, the animals receiving both DOX and BKM120 exhibited an even more dramatic reduction of tumor growth in either MDR cell xenograft (Figure 6a and b). Interestingly, the animals receiving DOX alone displayed a significant body weight (BW) loss ( 30\% reduction by day 45 as compared with the BW on day 15). In contrast, no significant BW loss was observed in the animals treated with BKM120 alone in either MDR cell xenograft (Figure 6c and d).

Consistent with our in vitro results, western blot results revealed that BKM120 treatment reduced phospho-AKT, total and nuclear NF-KB p65 subunit protein levels in xenograft tumor tissues (Figure 6e). Apoptosis-related genes including Bax, Bim and Survivin were also regulated by BKM120 in vivo (Figure 6f). Thus, BKM120 effectively blocks the aberrant activity of the PI3K/AKT/NF- $\kappa \mathrm{B}$ signaling pathway in chemoresistant breast cancer cells, which subsequently induces xenograft tumor regression in vivo.

\section{Discussion}

Most cytotoxic anticancer therapies are encumbered by the development of acquired resistance of cancer cells. Chemoresistance is a complex phenomenon involving multiple mechanisms. Reduction of drug accumulation, enhancement of DNA repair, impediment to apoptosis and alterations in cell cycle are believed to be the major causes of chemoresistance. Many of these factors are manifested in intracellular signaling pathways, and one of the most prominent is the PI3K/AKT pathway.

Here, we employed three drug-resistant human breast cancer cell lines for the experiments, MCF-7/A02, CALDOX and MD60, all of which possess the MDR phenotype but are caused by different mechanisms. The overexpression of $\mathrm{P}$-gp has been recognized as the most significant factor conferring chemoresistance of MCF-7/A02 and MD60. In contrast, compared with Cal51, CALDOX cells have no increased P-gp expression or any other drug transporters, implying that mechanisms independent of drug transporters have a leading role in chemoresistance of CALDOX cells. Despite that the causes of drug resistance in these cell lines are different, the $\mathrm{PI} 3 \mathrm{~K} / \mathrm{AKT} / \mathrm{NF}-K \mathrm{~B}$ signaling is overactivated in all three cell lines, which is consistent with the findings reported by other groups. ${ }^{10,12}$ Indeed, this crucial survival pathway promotes acquired resistance in a wide range of cancers, such as breast cancer, leukemia, ovarian cancer and non-small-cell lung carcinoma. ${ }^{39-41}$ Hence, novel therapeutics against this PI3K/ AKT/NF-KB pathway may offer new strategies to overcome drug resistance.

In this study, we examined the responses of three chemoresistant breast cancer cell lines to the PI3K inhibitor BKM120. Our studies were performed both in vitro and in vivo. The inhibition of PI3K by BKM120 results in a dramatic 
a
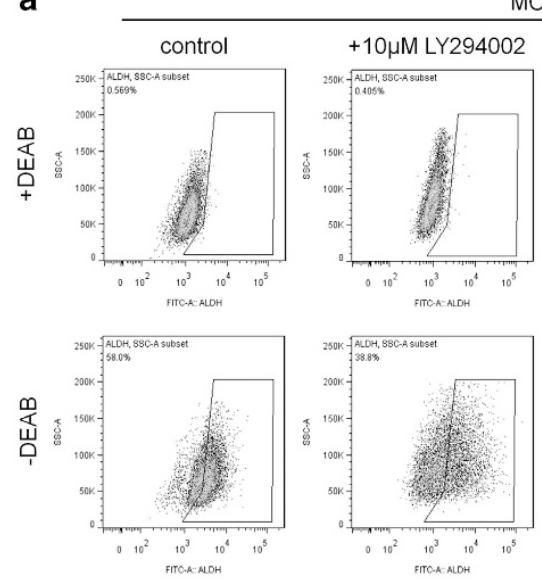

MCF-7/A02
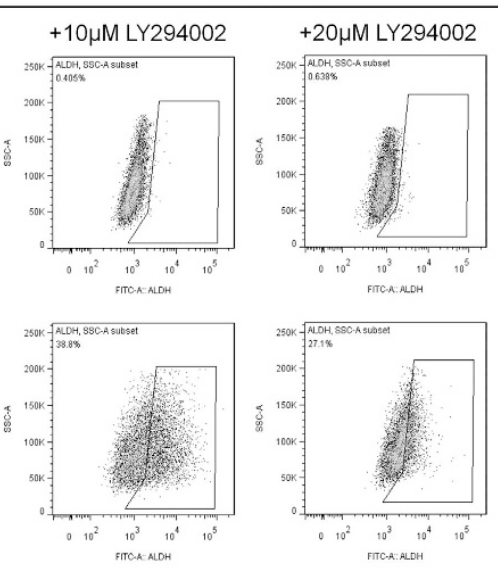

CALDOX
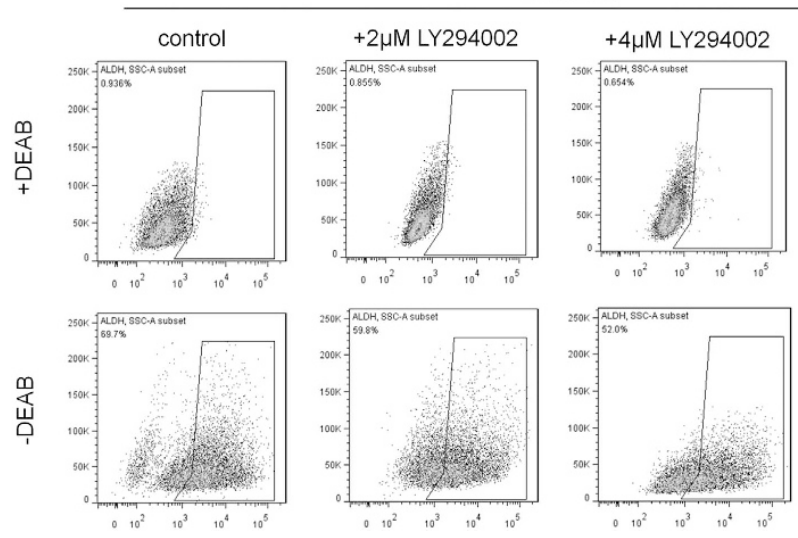

b

MCF-7/A02
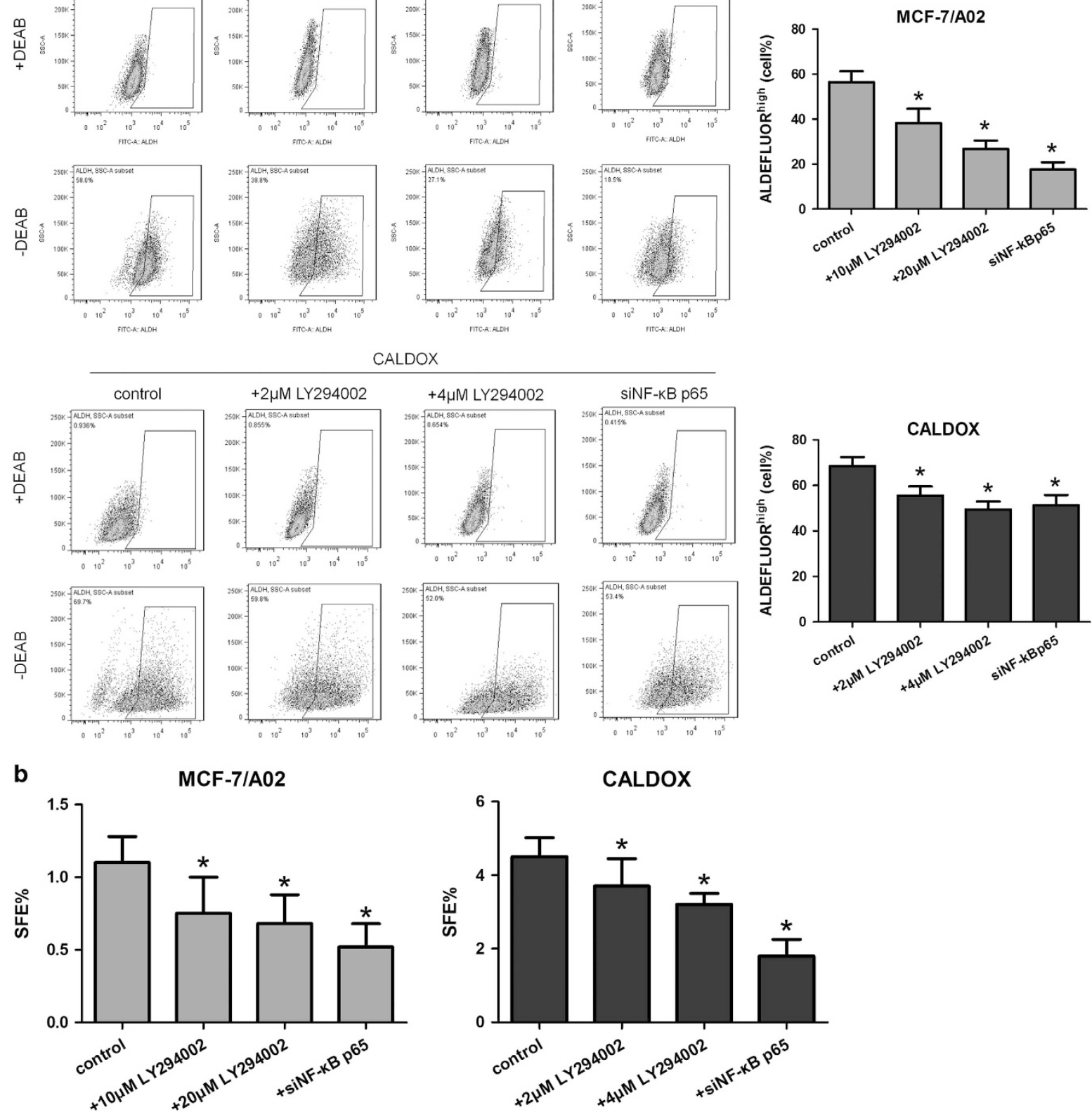

Figure 5 Inhibiting the PI3K/AKT/NF- $\mathrm{B} B$ signaling pathway diminishes breast cancer stem cell population. (a) Flow cytometry analysis of ALDH activity. Cells with LY294002 treatment for $48 \mathrm{~h}$ or after siRNA transfection for $72 \mathrm{~h}$ were assayed with an Aldefluor assay kit in the presence and absence of ALDH inhibitor DEAB. Gating in the control was set up to a maximum of $1 \%$ of cells. Representative plots of three independent experiments are shown. Quantitative data show the average percentage of ALDH ${ }^{\text {high }}$ cells \pm S.D. of three independent experiments (right panel). (b) Mammosphere-forming efficacy of cells with LY294002 treatment or siRNA transfection. SFE was calculated as the number of spheres formed in 10 days divided by the original number of single cells seeded and expressed as a percentage. Bars represent the mean percentage of mammospheres \pm S.D. from three separate experiments. ${ }^{*} P<0.05$

decrease in AKT phosphorylation and subsequent downregulation of NF- $\kappa B$. Furthermore, activation of caspase-3,7,9, inhibition of survivin expression, as well as augment of Bax and Bim expression, were also detected after BKM120 treatment. These are consistent with recent studies that BKM120 elevated Bim expression in chronic lymphocytic leukemia cells ${ }^{42}$ and induced Bax expression and caspase$3 / 7$ activation in glioma cell lines, T-cell acute lymphoblastic leukemia and ER-positive breast cancer cells. ${ }^{19,43,44}$ It is well known that AKT is a central node in the PI3K signaling pathway that activates a number of downstream pathways implicated in tumorigenesis. BKM120 has previously been shown to inhibit some other pathways, including the AKT/mTOR pathway in breast cancer and hepatocellular carcinoma, the AKT/GSK3/FBXW7 pathway in chronic lymphocytic leukemia cells and the AKT/FOXO3a axis in lung 
Table 2 Cytotoxicity of BKM120 and doxorubicin/etoposide to different breast cancer cell lines

\begin{tabular}{lccccc}
\hline MCF-7/A02 & & & & & \\
BKM120 $(\mu \mathrm{M})$ & 1 & 2 & 4 & 8 & 16 \\
Doxorubicin $(\mu \mathrm{M})$ & 5 & 10 & 20 & 40 & 80 \\
Cl & 0.368 & 0.279 & 0.184 & 0.241 & 0.144 \\
BKM120 $(\mu \mathrm{M})$ & 1 & 2 & 4 & 8 & 16 \\
Etoposide $(\mu \mathrm{M})$ & 15 & 30 & 60 & 120 & 240 \\
Cl & 0.262 & 0.531 & 0.355 & 0.471 & 0.138 \\
& & & & & \\
CALDOX & & & & & \\
BKM120 $(\mu \mathrm{M})$ & 0.5 & 1 & 2 & 4 & 8 \\
Doxorubicin $(\mu \mathrm{M})$ & 0.625 & 1.25 & 2.5 & 5 & 10 \\
Cl & 0.306 & 0.213 & 0.362 & 0.212 & 0.129 \\
BKM120 $(\mu \mathrm{M})$ & 0.5 & 1 & 2 & 4 & 8 \\
Etoposide $(\mu \mathrm{M})$ & 12.5 & 25 & 50 & 100 & 200 \\
Cl & 0.351 & 0.412 & 0.501 & 0.522 & 0.223 \\
& & & & & \\
\hline
\end{tabular}

cancer cells. ${ }^{42,45-47}$ Our study uncovers for the first time that BKM120 can also modulate NF-KB, another critical substrate of AKT. Importantly, NF- $k \mathrm{~B}$ signaling and cell apoptosis are frequently associated with many solid cancers, ${ }^{48,49}$ although the molecular mechanisms remain obscure. It is tempting to speculate that $A K T / N F-\kappa B$ represents a 'salvage pathway' that links BKM120 with apoptosis induction.

Comparing traditional chemotherapeutic agents such as doxorubicin and etoposide, BKM120 reduced cell viability more effectively in a concentration-dependent manner in all tested MDR breast cancer cells. Others also proved that therapy resistance could be partially overcome by downregulating $\mathrm{AKT} / \mathrm{NF}-\kappa \mathrm{B}$. For instance, salinomycin induced apoptosis in cisplatin-resistant ovarian cancer cells through inhibiting the AKT/NF- $\kappa$ B pathway. ${ }^{50}$ PS1145 can overcome imatinib resistance in leukemia through blocking the NF-KB pathway. ${ }^{29}$ LY294002, another important selective inhibitor of $\mathrm{PI} 3 \mathrm{~K}$, has been proven to overcome acquired resistance of 5$\mathrm{FU}$ in gastric cancer by modulating NF- $K \mathrm{~B}$ activity. ${ }^{51}$ Our study also demonstrated that the AKT/NF- $\kappa \mathrm{B}$ pathway blocked by LY294002 or NF-kB p65 siRNA led to apoptosis of MDR breast cancer cells. Although some studies reported that several AKT/NF- $k B$ inhibitors reverse the MDR phenotype by decreasing $\mathrm{P}$-gp expression, ${ }^{52,53}$ our data indicated that BKM120 did not alter $\mathrm{P}$-gp expression, suggesting that BKM120 overcame chemoresistance through inducing apoptosis, rather than increasing drug influx.

Accumulating evidence indicates that breast CSCs have a crucial role in therapy resistance and recurrence of breast cancers. ${ }^{5,54}$ Hence, breast CSCs are considered to be critical therapeutic targets, and elimination of breast CSCs may improve the outcomes of cancer chemotherapy. ${ }^{55}$ Recent studies indicate that the activation of the PI3K/AKT/NF- $K B$ pathway is indispensable for maintaining the stemness and chemoresistance of breast CSCs. ${ }^{56,57}$ Present and other studies have shown that PI3K inhibition sensitizes CSCs to chemotherapy and molecular targeted therapy in several cancers including leukemia, ${ }^{58}$ hepatocellular carcinoma ${ }^{59}$ and breast cancer. ${ }^{60}$ Moreover, the blockage of NF- $k$ B activity also provokes cytotoxic effects on CSCs in glioblastoma multiforme. ${ }^{61}$ In line with these results, our findings revealed that, in contrast to highly resistant to traditional chemotherapeutic agents, the CSC population of the three MDR cell lines tested remained relatively sensitive to BKM120-induced cytotoxicity. Furthermore, BKM120 remarkably eliminated CSCs in drug-resistant cells. After exposure to BKM120, the clonogenicity of resistant cells was evidently eradicated in vitro, and the $\mathrm{ALDH}{ }^{\text {high }}$ and CD $44^{\text {high }} / \mathrm{CD} 24^{\text {low }}$ population decreased obviously in the survival cells. In addition, LY294002 and NF-KB silencing also inhibited stemness significantly, indicating that targeting $\mathrm{PI} / \mathrm{K} / \mathrm{AKT} / \mathrm{NF}-\kappa \mathrm{B}$ pathway is emerged as a promising approach to kill CSCs and consequently surmount MDR in breast cancers.

BKM120 exerted a synergistic effect with doxorubicin both in vitro and in vivo. It has recently been reported that BKM120 in combination with trastuzumab is beneficial in trastuzumabresistant breast cancer. ${ }^{62}$ Other $\mathrm{PI} 3 \mathrm{~K}$ inhibitors, including LY294002 and buparlisib, have also been proven to have greater clinical efficacy combined with endocrine therapy. ${ }^{63,64}$ In some other solid tumors, BKM120 has been reported to synergistically work with an mTOR inhibitor RAD001 and a Bcl-2 inhibitor ABT-737 in suppression of lung cancer ${ }^{18}$ and glioblastoma cell growth, ${ }^{19}$ respectively. It is of note that these combined therapies were all well tolerated. Consistently, our study demonstrates that BKM120 sensitizes MDR breast cancer cells to cytotoxic drugs (doxorubicin and etoposide) using $\mathrm{Cl}$-isobologram analysis, suggesting that combination with BKM120 therapy can augment the cytotoxic activity of chemodrugs against MDR breast cancer growth but with no further toxicities.

Overall, the present study discloses that the MDR phenotype of breast cancer cells is associated with an aberrant activation of the $\mathrm{PI} / \mathrm{K} / \mathrm{AKT} / \mathrm{NF}-\kappa \mathrm{B}$ signaling pathway. Our findings establish that BKM120 effectively inhibits this signaling pathway, and provide strong evidence demonstrating that BKM120 potently induces cell apoptosis and aggressively eliminates breast CSCs in these MDR breast cancer cells. Moreover, the combination therapy of BKM120 and doxorubicin shows a synergistic effect both in vitro and in vivo. Our data suggest that targeting the PI3K/AKT/NF- $K B$ signaling pathway using selective inhibitors such as BKM120 can be a potential strategy for treatment of relapsed MDR breast cancers.

\section{Materials and Methods}

Cell culture. Human breast cancer cell line MCF-7 and its MDR counterpart MCF-7/A02 were gifts from Professor Dongsheng Xiong (Institute of Hematology, PUMC, Tianjin, China) and were cultured as previously described. ${ }^{65}$ Human breast cancer cell line Cal51 and its MDR counterpart CALDOX were gifts from Dr. Ernesto Yague (Imperial College London, UK) and were cultured as previously described. ${ }^{28}$ MTMEC and its doxorubicin-resistant derivative MD60 were also gifts from Dr. Ernesto Yague, and they were routinely maintained in a serum-free HuMEC medium (Life Technologies, Paisley, UK) as previously described. ${ }^{66}$ MTMEC is an immortalized human mammary epithelial cell line expressing TERT, SV40 large T antigen, a constitutively active form of PI3K, p110 $\alpha$ and oncogenic RAS. ${ }^{67}$ These cells were treated with chemotherapeutic drugs doxorubicin, etoposide, taxol (Sigma, St. Louis, MO, USA), PI3K inhibitors LY294002 (Cell Signaling Technology, Danvers, MA, USA) and NVP-BKM120 (Novartis, Basel, Switzerland) alone or in combination at various doses and durations.

Cell viability analysis. MTT (3-(4,5-Dimethylthiazol-2-yl)-2,5-diphenyltetrazolium bromide) assays were performed to evaluate the cell viability in response to drug treatments and were also used to determine the concentration of drug that inhibited cell growth by $50 \%\left(\mathrm{IC}_{50}\right)$ after 3 days of treatment. ${ }^{68}$ For drug combination experiments, a $\mathrm{Cl}$ number was calculated using the CalcuSyn software 
(Biosoft, Cambridge, UK) based on the Chou and Talalay method. $\mathrm{Cl}$ values between 0.1 and 0.9 define different grades of synergism: values between 0.9 and 1.1 are additive, whereas values $>1.1$ are antagonistic.
Drug resistance clonogenic assay. Cells at a density of $2 \times 10^{5}$ cells/well in six-well plates were treated with a single dose of doxorubicin ( $3 \mu \mathrm{M}$ for MCF-7 and MCF-7/A02, $0.2 \mu \mathrm{M}$ for Cal51 and CALDOX), or $2 \mu \mathrm{M}$ BKM120 for 1 week. a

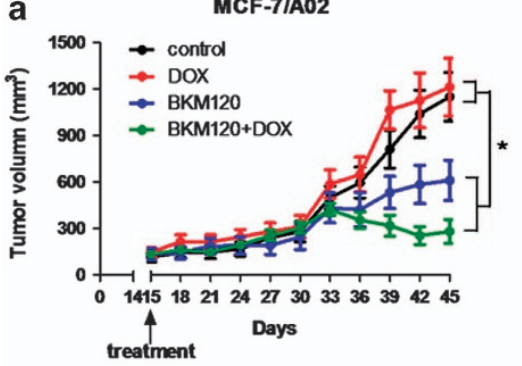

C

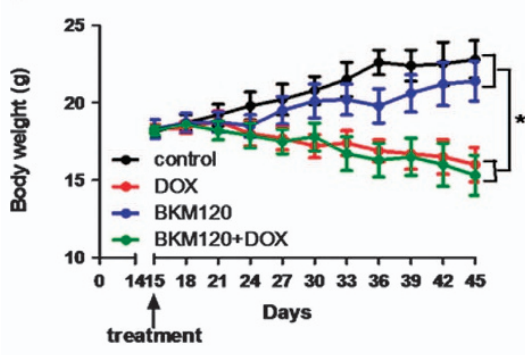

e

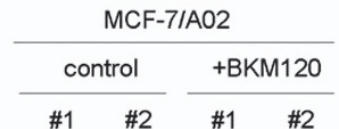

$65 \mathrm{kDa}$

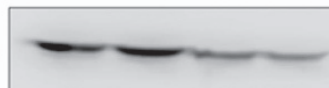

$65 \mathrm{kDa}$

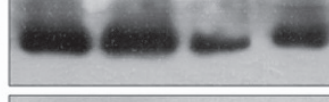

$60 \mathrm{kDa}$

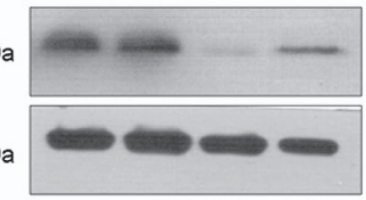

Total NF- $\mathrm{k} B$ p65 PAKT

$60 \mathrm{kDa}$

AKT

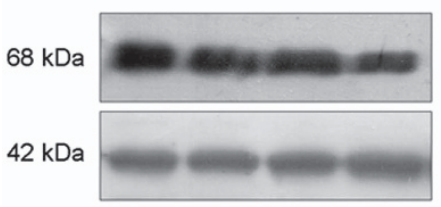

Lamin B

$\beta$-actin

\section{f}

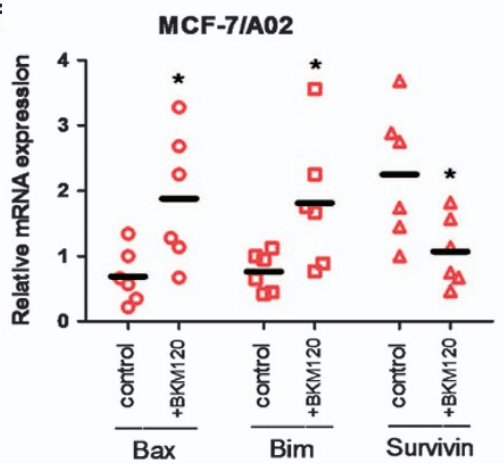

b

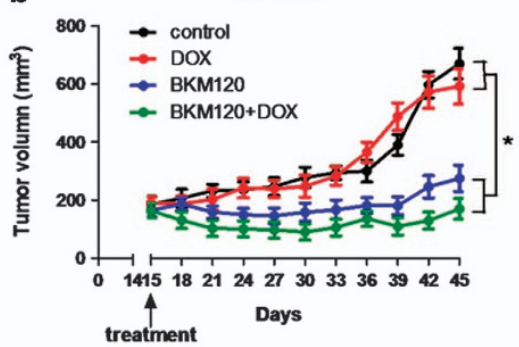

d

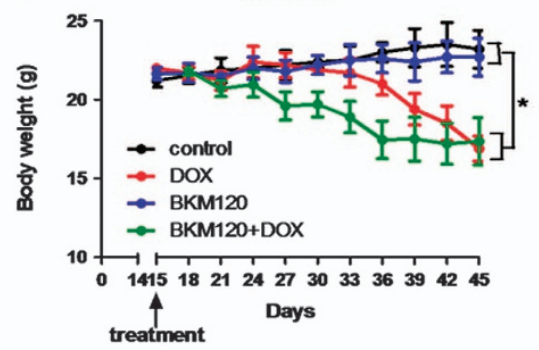

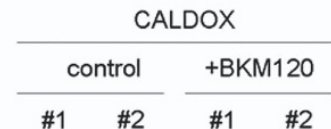
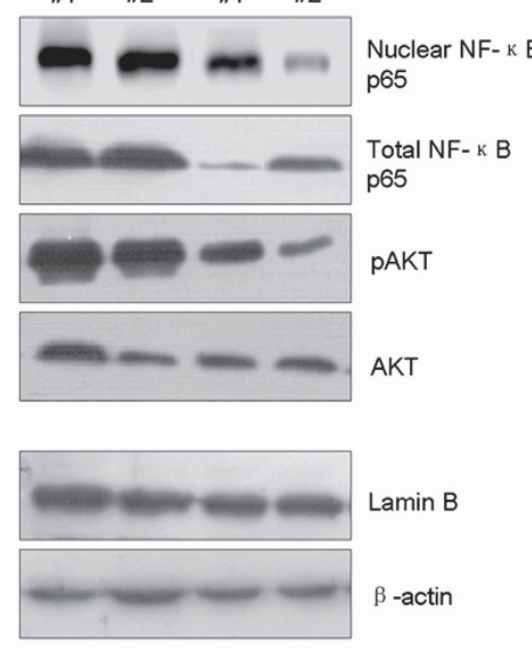

CALDOX

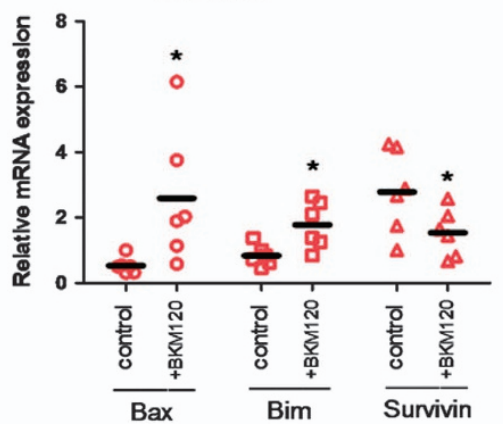


Resistant clones were fixed with $4 \%$ paraformaldehyde and stained with $0.2 \%$ crystal violet and counted. Crystal violet retained in the cells was solubilized with $0.5 \%$ acetic acid and quantified by measurement of optical density at $592 \mathrm{~nm}$.

siRNA transfection. Cells at a density of $3 \times 10^{5}$ cells/well in six-well plates were used for siRNA transfection. Briefly, $50 \mathrm{nM}$ siRNA against the NF- $\mathrm{B}$ p 65 subunit or scrambled siRNA control (GenePharma Company, Shanghai, China) was mixed with lipofectamine 3000 (Life Technologies, Grand Island, NY, USA) and then added to each well. The effects of siRNA on NF- $\kappa$ B p 65 subunit mRNA and protein levels were examined 48 and $72 \mathrm{~h}$ after transfection, respectively.

Protein extraction and western blotting. A modified RIPA buffer $(50 \mathrm{mM}$ Tris- $\mathrm{HCl}, 150 \mathrm{mM} \mathrm{NaCl}, 0.25 \%$ SDS, $1 \%$ Triton X-100, $0.25 \%$ sodium deoxycholate, $1 \mathrm{mM}$ EDTA, $1 \mathrm{mM}$ EGTA and $1 \mathrm{mM}$ dithiothreitol) with protease inhibitor cocktail (Sigma) was used for protein isolation from whole cells or nuclear fraction. Cell nuclei were isolated using a Nuclei EZ Prep Kit (Sigma) according to the instruction recommended by the manufacturer. Protein concentrations were determined using the BCA Protein Assay Kit (Pierce, Rockford, IL, USA). An equal quantity $(50 \mu \mathrm{g})$ of proteins was resolved on $12 \%$ polyacrylamide gels and transferred to nitrocellulose membranes (Millipore, Billerica, MA, USA), and then blocked with $5 \%$ blotting grade milk (Bio-Rad, Hercules, CA, USA) in PBST (0.1\% Tween 20 in phosphate-buffered saline (PBS)). The membranes were incubated with primary antibodies to phosphoAKT (D9E), AKT1 (C73H10), Bax (D2E11), Bim (C34C5; Cell Signaling Technology), Survivin (ab76424, Abcam, Cambridge, UK) and NF-kB p65 (sc372, Santa Cruz Biotechnology, Dallas, TX, USA) at $4{ }^{\circ} \mathrm{C}$ overnight. The peroxidaseconjugated anti-rabbit IgG secondary antibody (Cell Signaling Technology) was incubated with the membranes for $2 \mathrm{~h}$ at room temperature. Immunoblotting signals were detected using the SuperSignal West Pico Chemiluminescent Substrate (Pierce) according to the instruction suggested by the manufacturer. All the membranes were re-probed with anti- $\beta$-actin (sc47778) or lamin B (sc6216) antibodies (Santa Cruz Biotechnology), which served as loading controls.

RNA isolation and RT-qPCR. Total RNA was isolated using Trizol (Invitrogen, Carlsbad, CA, USA) following the procedure suggested by the manufacturer. The cDNA was generated using OligdT primers and SuperScript III reverse transcriptase (Invitrogen) using $2 \mu \mathrm{g}$ total RNA. Specific primers for each gene (Supplementary Table S3) were designed using the Primer Express program (Applied Biosystems, Foster City, CA, USA). Quantitative real-time PCR was carried out using SYBR Green I (Takara, Dalian, China) and detected using an ABI SDS7900 Real-time PCR system (Applied Biosystems). A standard curve for each gene was included in each PCR amplification for calculation of the $C_{\mathrm{t}}$ value. Relative transcript levels were normalized with RPS14.

Annexin V staining. Cell apoptosis was assessed using an Annexin $\mathrm{V}$ - fluorescein isothiocyanate (FITC) and PI double-staining apoptosis detection kit (Becton Dickinson, Mountain View, CA, USA) according to the procedure suggested by the manufacturer. Briefly, cells $\left(2 \times 10^{5}\right)$ were washed twice with PBS and suspended in $100 \mu \mathrm{l}$ binding buffer followed by staining with $5 \mu \mathrm{l}$ Annexin V-FITC and $5 \mu \mathrm{l} \mathrm{PI}$ for $15 \mathrm{~min}$ in the dark at room temperature. The fluorescence was measured with a flow cytometer (BD FACSCanto II, Becton Dickinson). Quantitative data show the average percentage of annexin V-positive cells (both in early apoptosis, LR quadrant, and late apoptosis, UR quadrant) of three independent experiments.

Drug accumulation assay. The relative cellular accumulation of tracer dye Rhodamine123 (Sigma) was determined using flow cytometry as described before. ${ }^{69}$ Briefly, MCF-7/A02 cells were collected $48 \mathrm{~h}$ after being treated with BKM120 and then incubated with $0.3 \mu \mathrm{M}$ Rhodamine123 in RPMl1640 medium with constant shaking for $90 \mathrm{~min}$ at $37^{\circ} \mathrm{C}$. After washing twice with ice-cold PBS, the cells were resuspended in $500 \mu \mathrm{l}$ ice-cold PBS. Rhodamine123 accumulation in cells was determined using a flow cytometer (BD FACSCanto II, Becton Dickinson). The cells were excited at $488 \mathrm{~nm}$, and emission was measured at $530 \mathrm{~nm}$.

Analysis of $\mathrm{CD}^{4} 4^{+} / \mathrm{CD}^{-} 4^{-}$cell subpopulation. For stem cell marker analysis, APC-conjugated CD44 and phycoerythrin (PE)-conjugated CD24 monoclonal antibodies (BD Biosciences, San Jose, CA, USA) were used as described by Lombardo et al..$^{31}$ Briefly, cells were harvested $48 \mathrm{~h}$ after treatment and suspended in PBS at $1 \times 10^{6}$ cells/ml. Both APC-CD44 and PE-CD24 antibodies or their respective isotype controls APC-lgG and PE-lgG were added to the cell suspensions at concentrations recommended by the manufacturer and incubated for $40 \mathrm{~min}$ at $4{ }^{\circ} \mathrm{C}$ in the dark. The labeled cells were washed in PBS and then analyzed with a flow cytometry (BD FACSCanto II, Becton Dickinson). Gating was set to relevant isotype control (APC-IgG and PE-lgG)-labeled cells for each cell line.

Aldefluor assay. An Aldefluor assay kit (StemCell Technologies, Vancouver, BC, Canada) was used for the determination of ALDH activity with flow cytometry as described by Hu et al. ${ }^{66}$ Briefly, cells were harvested $48 \mathrm{~h}$ after treatment and suspended in Aldefluor assay buffer at $1 \times 10^{6} \mathrm{cell} / \mathrm{s} / \mathrm{ml}$. As a negative control, half the sample was transferred to a tube containing $5 \mu$ l of the ALDH inhibitor diethylaminobenzaldehyde. Activated Aldefluor substrate $(5 \mu l)$ was added to both samples and incubated at $37^{\circ} \mathrm{C}$ for $45 \mathrm{~min}$ to allow substrate conversion. The cells were resuspended in Aldefluor assay buffer and analyzed using a flow cytometer (BD FACSCanto II, Becton Dickinson).

Electrophoretic mobility shift assay. Electrophoretic mobility shift assay (EMSA) for NF- $k \mathrm{~B}$ was performed using Lightshift Chemiluminescent EMSA kits (Thermo Fisher Scientific, Bonn, Germany) according to the procedure suggested by the manufacturer. Annealed oligonucleotides containing NF- $\kappa B-b i n d i n g$ site (5'-AGTTGAGGGGACTTTCCCAGGC-3' and 3'-TCAACTCCCCTGAAAGGGTCC G- $5^{\prime}$ ) were end-labeled using a biotin $3^{\prime}$ end-labeling kit (Thermo Fisher Scientific). Briefly, $5 \mathrm{pmol}$ double-stranded oligonucleotides were incubated in a $50-\mu \mathrm{l}$ reaction buffer containing $10 \mu \mathrm{l}$ of $5 \times$ terminal deoxynucleotidyl transferase (TdT) buffer, $5 \mu \mathrm{l}$ of $5 \mu \mathrm{M}$ biotin-N-4-CTP, $10 \mathrm{U}$ of diluted TdT and $25 \mu \mathrm{l}$ of ultra-pure water at $37^{\circ}$ $\mathrm{C}$ for $30 \mathrm{~min}$. DNA-protein complexes were prepared by mixing $50 \mathrm{fmol}$ biotin-endlabeled oligonucleotides and $5 \mu$ l nuclear extracts in $1 \times$ binding buffer. DNA-protein complexes and free DNA were separated on a native polyacrylamide gel and transferred to a nylon membrane. The membrane was subsequently incubated with streptavidin-horseradish peroxidase conjugate and a chemiluminescent substrate. DNA-protein complexes were visualized by exposure to $\mathrm{X}$-ray films.

Caspase activity measurement. Cells $\left(1 \times 10^{4}\right)$ were incubated with BKM120 or LY294002 in a 96-well plate for $24 \mathrm{~h}$. The caspase-3/7 and caspase-9 activities were measured using the Caspase-Glo 3/7 Assay and Caspase-Glo 9 Assay Kits, respectively (Promega, Madison, WI, USA) following the protocol recommended by the manufacturer. Fluorescence was measured using a GloMax 20/20 Luminometer (Promega). z-VAD-fmk (Selleck, Houston, TX, USA) was used as a pancaspase inhibitor.

Immunofluorescence staining. Cells were seeded on square coverslips in six-well plates. Subsequently, cells were fixed with $2 \%$ paraformaldehyde for $15 \mathrm{~min}$, permeabilized with $0.2 \%$ Triton X-100 for 5 min and blocked with $3 \%$ BSA for $30 \mathrm{~min}$. The coverslips were then incubated with rabbit anti-NF- $\mathrm{B}$ p 65 primary antibody for $1 \mathrm{~h}$ at room temperature followed by Alexafluor 488-labeled secondary antibody (Santa Cruz Biotechnology) for $1 \mathrm{~h}$ at room temperature. The coverslips were counterstained with $1 \mathrm{mg} / \mathrm{ml}$ 4',6-Diamidino-2-phenylindole (Sigma) for $10 \mathrm{~min}$ to visualize the cell nucleus. All antibodies and staining reagents were diluted in PBS containing $3 \%$ BSA. The cells were washed three times with PBS after each

Figure 6 The antitumor activity of BKM120 in MCF-7/A02 and CALDOX xenograft tumors. (a and b) Tumor sizes of MCF-7/A02 (a) and CALDOX (b) xenografts after treatment with PBS (control), DOX, BKM120 or BKM120 plus DOX. Data are presented as the mean tumor size \pm S.D. of six mice per group. (c and d) Body weight of nude mice bearing MCF-7/A02 (c) and CALDOX (d) xenografts treated with PBS (control), DOX, BKM120 or BKM120 plus DOX. Data are presented as the mean body weight \pm S.D. of six mice per group. (e) Western blot analysis of pAKT, AKT, nuclear NF- $\kappa B$ p65 and total NF- $\kappa B$ p65 on MCF-7/A02 and CALDOX derived tumors treated with BKM120 or PBS. Tumors were obtained from two mice randomly chosen from six mice per group. Both lamin B and $\beta$-actin were used as loading controls. (f) Relative fold of Bax, Bim and Survivin gene expression levels in MCF-7/A02 and CALDOX derived tumors treated with BKM120 or PBS. ${ }^{*} P<0.05$ 
step of the staining procedures. The coverslips were covered with ProLong Gold antifade mounting medium (Invitrogen) and then were viewed and photographed with a Zeiss LSM 510 Meta fluorescence microscope (Zeiss, Jena, Germany).

Soft agar colony formation assay. Cells were disassociated and suspended in DMEM or HuMEC medium containing $0.3 \%$ agar and plated on the top of a solidified layer of $0.6 \%$ agar. The cells were plated at a density of $2 \times 10^{5}$ cells/well in six-well plates, and the colonies were counted 21 days later.

Mammosphere culture. Cells $\left(1 \times 10^{3}\right)$ were plated in each well of an ultralow attachment plate (Corning Incorporated, Corning, NY, USA) with $3 \mathrm{ml}$ serum-free mammary epithelial growth medium (MEGM, BioWhittaker, Walkersville, MD, USA), supplemented with B27 (Invitrogen), $20 \mathrm{ng} / \mathrm{ml} \mathrm{EGF} \mathrm{and} 20 \mathrm{ng} / \mathrm{ml}$ basic FGF (BD Biosciences). Colony formation was assessed 10 days later.

In vivo xenografts. Cells $\left(1 \times 10^{7}\right)$ were suspended in $100 \mu$ l PBS containing $50 \%$ Matrigel (BD Biosciences) and injected into the mammary fat pad of 4-5-weekold female nude mice (Vital River Company, Beijing, China). Tumor sizes were measured every 3 days in two dimensions using a caliper, and the tumor volume was calculated with the following formula: tumor volume $\left(\mathrm{mm}^{3}\right)=0.5 \times a b^{2}$ ( $a$ and $b$ being the longest and shortest diameters of the tumor, respectively). Fourteen days after cell injection, the tumor-bearing mice were randomly divided into four groups (six animals/group): (1) control group (normal saline), (2) BKM120 group (50 mg BKM120 per $\mathrm{kg} \mathrm{BW}$ ), (3) DOX group (2 mg doxorubicin per $\mathrm{kg} \mathrm{BW}$ ) and (4) BKM120+DOX group (50 mg BKM120 and $2 \mathrm{mg}$ DOX per kg BW). Drugs were injected every 3 days, and tumor volumes were monitored till the mice were killed. Mice were killed in a humane manner, and the tumors were collected for protein extraction and RNA extraction. All mice were maintained as required under the National Institutes of Health guidelines for the Care and Use of Laboratory Animals. The use of animals in this study has been approved by the Animal Care and Use Committee of Tianjin Cancer Hospital.

Statistical analysis. Comparisons of the means among more than two groups were performed by one-way analysis of variance. Student's $t$-test was used when comparing the means of two groups. A $P$-value $<0.05$ was considered statistically significant.

\section{Conflict of Interest}

The authors declare no conflict of interest.

Acknowledgements. We thank Professor Dongsheng Xiong (Institute of Hematology, PUMC, Tianjin, China) for a generous gift of human breast cancer cells MCF-7 and MCF-7/A02. We thank Dr. Ernesto Yagüe (Imperial College London, UK) for a generous gift of human breast cancer cells Cal51, CALDOX, MTMEC and MD60. We also thank Professor Zhenmin Lei and Dr. Ernesto Yague for helpful comments to the manuscript. This work was supported by the Chinese National Natural Sciences Foundation (81402480 to YH), the Science and Technology Foundation of Tianjin Municipal Health Bureau (2014KZO78 to YH) and Tianjin municipal Major Scientific and Technological Special Project for Significant Anticancer Development (12ZCDZSY15700 to ZJ).

1. Hennessy M, Spiers JP. A primer on the mechanics of P-glycoprotein the multidrug transporter. Pharmacol Res 2007; 55: 1-15.

2. Steinbach $D$, Legrand $O$. $A B C$ transporters and drug resistance in leukemia: was P-gp nothing but the first head of the Hydra? Leukemia 2007; 21: 1172-1176.

3. Niero EL, Rocha-Sales B, Lauand C, Cortez BA, de Souza MM, Rezende-Teixeira P et al. The multiple facets of drug resistance: one history, different approaches. J Exp Clin Cancer Res 2014; 33: 37.

4. Xia H, Hui KM. Mechanism of cancer drug resistance and the involvement of noncoding RNAs. Curr Med Chem 2014; 21: 3029-3041.

5. Dean M, Fojo T, Bates S. Tumour stem cells and drug resistance. Nat Rev Cancer 2005; 5: 275-284.

6. Takebe N, Harris PJ, Warren RQ, Ivy SP. Targeting cancer stem cells by inhibiting Wnt, Notch, and Hedgehog pathways. Nat Rev Clin Oncol 2011; 8: 97-106.

7. Touil Y, Zuliani T, Wolowczuk I, Kuranda K, Prochazkova J, Andrieux J et al. The PI3K/AKT signaling pathway controls the quiescence of the low-Rhodamine123-retention cell compartment enriched for melanoma stem cell activity. Stem Cells 2013; 31: 641-651.
8. Zhu Y, Yu F, Jiao Y, Feng J, Tang W, Yao H et al. Reduced miR-128 in breast tumor-initiating cells induces chemotherapeutic resistance via Bmi-1 and ABCC5. Clin Cancer Res 2011; 17: 7105-7115.

9. Li X, Lewis MT, Huang J, Gutierrez C, Osborne CK, Wu MF et al. Intrinsic resistance of tumorigenic breast cancer cells to chemotherapy. J Natl Cancer Inst 2008; 100: 672-679.

10. Cheng JQ, Lindsley CW, Cheng GZ, Yang H, Nicosia SV. The Akt/PKB pathway: molecular target for cancer drug discovery. Oncogene 2005; 24: 7482-7492.

11. Andre F, Nahta R, Conforti R, Boulet T, Aziz M, Yuan LX et al. Expression patterns and predictive value of phosphorylated AKT in early-stage breast cancer. Ann Oncol 2008; 19: 315-320.

12. Liang K, Lu Y, Li X, Zeng X, Glazer RI, Mills GB et al. Differential roles of phosphoinositidedependent protein kinase-1 and akt1 expression and phosphorylation in breast cancer cell resistance to Paclitaxel, Doxorubicin, and gemcitabine. Mol Pharmacol 2006; 70: 1045-1052.

13. Cidado J, Park BH. Targeting the PI3K/Akt/mTOR pathway for breast cancer therapy. J Mammary Gland Biol Neoplasia 2012; 17: 205-216.

14. Maira SM, Pecchi S, Huang A, Burger M, Knapp M, Sterker D et al. Identification and characterization of NVP-BKM120, an orally available pan-class I PI3-kinase inhibitor. Mol Cancer Ther 2012; 11: 317-328.

15. Zheng Y, Yang J, Qian J, Zhang L, Lu Y, Li H et al. Novel phosphatidylinositol 3-kinase inhibitor NVP-BKM120 induces apoptosis in myeloma cells and shows synergistic antimyeloma activity with dexamethasone. J Mol Med (Berl) 2012; 90: 695-706.

16. Amrein L, Shawi M, Grenier J, Aloyz R, Panasci L. The phosphatidylinositol-3 kinase I inhibitor BKM120 induces cell death in B-chronic lymphocytic leukemia cells in vitro. Int J Cancer 2013; 133: 247-252.

17. Bendell JC, Rodon J, Burris HA, de Jonge M, Verweij J, Birle D et al. Phase I, doseescalation study of BKM120, an oral pan-Class I PI3K inhibitor, in patients with advanced solid tumors. J Clin Oncol 2012; 30: 282-290.

18. Ren $\mathrm{H}$, Chen M, Yue P, Tao H, Owonikoko TK, Ramalingam SS et al. The combination of RAD001 and NVP-BKM120 synergistically inhibits the growth of lung cancer in vitro and in vivo. Cancer Lett 2012; 325: 139-146.

19. Jane EP, Premkumar DR, Morales A, Foster KA, Pollack IF. Inhibition of phosphatidylinositol 3-kinase/AKT signaling by NVP-BKM120 promotes ABT-737-induced toxicity in a caspasedependent manner through mitochondrial dysfunction and DNA damage response in established and primary cultured glioblastoma cells. J Pharmacol Exp Ther 2014; 350: 22-35.

20. O'Brien NA, McDonald K, Tong L, von Euw E, Kalous O, Conklin D et al. Targeting PI3K/ mTOR overcomes resistance to HER2-targeted therapy independent of feedback activation of AKT. Clin Cancer Res 2014; 20: 3507-3520.

21. Liu R, He B, Li D, Lai Y, Chang J, Tang JZ et al. Effects of pH-sensitive chain length on release of doxorubicin from mPEG-b-PH-b-PLLA nanoparticles. Int J Nanomed 2012; 7: 4433-4446.

22. Okamoto-Kubo S, Nishio K, Heike Y, Yoshida M, Ohmori T, Saijo N. Apoptosis induced by etoposide in small-cell lung cancer cell lines. Cancer Chemother Pharmacol 1994; 33: 385-390.

23. Cosse JP, Sermeus A, Vannuvel K, Ninane N, Raes M, Michiels C. Differential effects of hypoxia on etoposide-induced apoptosis according to the cancer cell lines. Mol Cancer 2007; 6: 61.

24. Chakrabarty A, Bhola NE, Sutton C, Ghosh R, Kuba MG, Dave B et al. Trastuzumabresistant cells rely on a HER2-PI3K-FoxO-survivin axis and are sensitive to PI3K inhibitors. Cancer Res 2013; 73: 1190-1200.

25. Tazzari PL, Cappellini A, Ricci F, Evangelisti C, Papa V, Grafone T et al. Multidrug resistance-associated protein 1 expression is under the control of the phosphoinositide 3 kinase/Akt signal transduction network in human acute myelogenous leukemia blasts. Leukemia 2007; 21: 427-438.

26. Clark AS, West K, Streicher S, Dennis PA. Constitutive and inducible Akt activity promotes resistance to chemotherapy, trastuzumab, or tamoxifen in breast cancer cells. Mol Cancer Ther 2002; 1: 707-717.

27. Ma X, Cai Y, He D, Zou C, Zhang P, Lo CY et al. Transient receptor potential channel TRPC5 is essential for P-glycoprotein induction in drug-resistant cancer cells. Proc Natl Acad Sci USA 2012; 109: 16282-16287.

28. Raguz S, Adams C, Masrour N, Rasul S, Papoutsoglou P, Hu Y et al. Loss of O(6)methylguanine-DNA methyltransferase confers collateral sensitivity to carmustine in topoisomerase II-mediated doxorubicin resistant triple negative breast cancer cells. Biochem Pharmacol 2013; 85: 186-196.

29. Cilloni D, Messa F, Arruga F, Defilippi I, Morotti A, Messa E et al. The NF-kappaB pathway blockade by the IKK inhibitor PS1145 can overcome imatinib resistance. Leukemia 2006; 20: 61-67.

30. Liu P, Kumar IS, Brown S, Kannappan V, Tawari PE, Tang JZ et al. Disulfiram targets cancer stem-like cells and reverses resistance and cross-resistance in acquired paclitaxel-resistant triple-negative breast cancer cells. Br J Cancer 2013; 109: 1876-1885.

31. Lombardo Y, Filipovic A, Molyneux G, Periyasamy M, Giamas G, Hu Y et al. Nicastrin regulates breast cancer stem cell properties and tumor growth in vitro and in vivo. Proc Natl Acad Sci USA 2012; 109: 16558-16563.

32. Ginestier C, Hur MH, Charafe-Jauffret E, Monville F, Dutcher J, Brown M et al. ALDH1 is a marker of normal and malignant human mammary stem cells and a predictor of poor clinical outcome. Cell Stem Cell 2007; 1: 555-567. 
33. Thiery JP, Acloque H, Huang RY, Nieto MA. Epithelial-mesenchymal transitions in development and disease. Cell 2009; 139: 871-890.

34. Ponti D, Costa A, Zaffaroni N, Pratesi G, Petrangolini G, Coradini D et al. Isolation and in vitro propagation of tumorigenic breast cancer cells with stem/progenitor cell properties. Cancer Res 2005; 65: 5506-5511.

35. Grimshaw MJ, Cooper L, Papazisis K, Coleman JA, Bohnenkamp HR, Chiapero-Stanke L et al. Mammosphere culture of metastatic breast cancer cells enriches for tumorigenic breast cancer cells. Breast Cancer Res 2008; 10: R52.

36. Miller TW, Balko JM, Arteaga CL. Phosphatidylinositol 3-kinase and antiestrogen resistance in breast cancer. J Clin Oncol 2011; 29: 4452-4461.

37. Ghebeh H, Al-Khaldi S, Olabi S, Al-Dhfyan A, Al-Mohanna F, Barnawi R et al. Fascin is involved in the chemotherapeutic resistance of breast cancer cells predominantly via the PI3K/Akt pathway. Br J Cancer 2014; 111: 1552-1561

38. Burris HA 3rd. Overcoming acquired resistance to anticancer therapy: focus on the PI3K AKT/mTOR pathway. Cancer Chemother Pharmacol 2013; 71: 829-842.

39. Fumarola C, Bonelli MA, Petronini PG, Alfieri RR. Targeting PI3K/AKT/mTOR pathway in non small cell lung cancer. Biochem Pharmacol 2014; 90: 197-207.

40. Polak R, Buitenhuis M. The PI3K/PKB signaling module as key regulator of hematopoiesis: implications for therapeutic strategies in leukemia. Blood 2012; 119: 911-923.

41. Koti M, Gooding RJ, Nuin P, Haslehurst A, Crane C, Weberpals J et al. Identification of the IGF1/PI3K/NF kappaB/ERK gene signalling networks associated with chemotherapy resistance and treatment response in high-grade serous epithelial ovarian cancer. BMC Cancer 2013; 13: 549 .

42. Rosich L, Saborit-Villarroya I, Lopez-Guerra M, Xargay-Torrent S, Montraveta A, Aymerich M et al. The phosphatidylinositol-3-kinase inhibitor NVP-BKM120 overcomes resistance signals derived from microenvironment by regulating the Akt/FoxO3a/Bim axis in chronic lymphocytic leukemia cells. Haematologica 2013; 98: 1739-1747.

43. Miller TW, Balko JM, Fox EM, Ghazoui Z, Dunbier A, Anderson H et al. ERalpha-dependent E2F transcription can mediate resistance to estrogen deprivation in human breast cancer. Cancer Discov 2011; 1: 338-351.

44. Lonetti A, Antunes IL, Chiarini F, Orsini E, Buontempo F, Ricci $F$ et al. Activity of the panclass I phosphoinositide 3-kinase inhibitor NVP-BKM120 in T-cell acute lymphoblastic leukemia. Leukemia 2014; 28: 1196-1206.

45. Bradford LS, Rauh-Hain A, Clark RM, Groeneweg JW, Zhang L, Borger D et al. Assessing the efficacy of targeting the phosphatidylinositol 3-kinase/AKT/mTOR signaling pathway in endometrial cancer. Gynecol Oncol 2014; 133: 346-352.

46. Ren H, Zhao L, Li Y, Yue P, Deng X, Owonikoko TK et al. The PI3 kinase inhibitor NVPBKM120 induces GSK3/FBXW7-dependent Mcl-1 degradation, contributing to induction of apoptosis and enhancement of TRAIL-induced apoptosis. Cancer Lett 2013; 338: 229-238.

47. Liu WL, Gao M, Tzen KY, Tsai CL, Hsu FM, Cheng AL et al. Targeting Phosphatidylinositide3-Kinase/Akt pathway by BKM120 for radiosensitization in hepatocellular carcinoma. Oncotarget 2014; 5: 3662-3672.

48. Arumugam TV, Cheng YL, Choi Y, Choi YH, Yang S, Yun YK et al. Evidence that gammasecretase-mediated Notch signaling induces neuronal cell death via the nuclear factorkappaB-Bcl-2-interacting mediator of cell death pathway in ischemic stroke. Mol Pharmaco 2011; 80: 23-31.

49. Dai Y, Lawrence TS, Xu L. Overcoming cancer therapy resistance by targeting inhibitors of apoptosis proteins and nuclear factor-kappa B. Am J Transl Res 2009; 1: 1-15.

50. Parajuli B, Lee HG, Kwon SH, Cha SD, Shin SJ, Lee GH et al. Salinomycin inhibits Akt/NFkappaB and induces apoptosis in cisplatin resistant ovarian cancer cells. Cancer Epidemiol 2013; 37: 512-517

51. Shin JY, Kim JO, Lee SK, Chae HS, Kang JH. LY294002 may overcome 5-FU resistance via down-regulation of activated p-AKT in Epstein-Barr virus-positive gastric cancer cells. BMC Cancer 2010; 10: 425 .

52. Chiarini F, Del Sole M, Mongiorgi S, Gaboardi GC, Cappellini A, Mantovani I et at. The novel Akt inhibitor, perifosine, induces caspase-dependent apoptosis and downregulates $\mathrm{P}$-glycoprotein expression in multidrug-resistant human T-acute leukemia cells by a JNK-dependent mechanism. Leukemia 2008; 22: 1106-1116.

53. Lin X, Zhang X, Wang Q, Li J, Zhang P, Zhao M et al. Perifosine downregulates MDR1 gene expression and reverses multidrug-resistant phenotype by inhibiting PI3K/Akt/NF-kappaB signaling pathway in a human breast cancer cell line. Neoplasma 2012; 59: 248-256.
54. Calcagno AM, Salcido CD, Gillet JP, Wu CP, Fostel JM, Mumau MD et al. Prolonged drug selection of breast cancer cells and enrichment of cancer stem cell characteristics. J Natl Cancer Inst 2010; 102: 1637-1652.

55. Gupta PB, Onder TT, Jiang G, Tao K, Kuperwasser C, Weinberg RA et al. Identification of selective inhibitors of cancer stem cells by high-throughput screening. Cell 2009; 138: 645-659.

56. Kendellen MF, Bradford JW, Lawrence CL, Clark KS, Baldwin AS. Canonical and noncanonical NF-kappaB signaling promotes breast cancer tumor-initiating cells. Oncogene 2014; 33: 1297-1305

57. Shostak K, Chariot A. NF-kappaB, stem cells and breast cancer: the links get stronger. Breast Cancer Res 2011; 13: 214.

58. Airiau K, Mahon FX, Josselin M, Jeanneteau M, Belloc F. PI3K/mTOR pathway inhibitors sensitize chronic myeloid leukemia stem cells to nilotinib and restore the response of progenitors to nilotinib in the presence of stem cell factor. Cell Death Dis 2013; 4: e827.

59. Wang XQ, Ongkeko WM, Chen L, Yang ZF, Lu P, Chen KK et al. Octamer 4 (Oct4) mediates chemotherapeutic drug resistance in liver cancer cells through a potential Oct4-AKT-ATPbinding cassette G2 pathway. Hepatology 2010; 52: 528-539.

60. Zhang X, Zhang S, Liu Y, Liu J, Ma Y, Zhu Y et al. Effects of the combination of RAD001 and docetaxel on breast cancer stem cells. Eur J Cancer 2012; 48: 1581-1592.

61. Liu P, Brown S, Goktug T, Channathodiyil P, Kannappan V, Hugnot JP et al. Cytotoxic effect of disulfiram/copper on human glioblastoma cell lines and ALDH-positive cancer-stemlike cells. Br J Cancer 2012; 107: 1488-1497.

62. O'Brien NA, McDonald K, Tong L, von Euw E, Kalous O, Conklin D et al. Targeting PI3K mTOR overcomes resistance to HER2-targeted therapy independent of feedback activation of AKT. Clin Cancer Res 2014; 20: 3507-3520.

63. Chen X, Zhao M, Hao M, Sun X, Wang J, Mao Y et al. Dual inhibition of PI3K and mTOR mitigates compensatory AKT activation and improves tamoxifen response in breast cancer. Mol Cancer Res 2013; 11: 1269-1278.

64. Mayer IA, Abramson VG, Isakoff SJ, Forero A, Balko JM, Kuba MG et al. Stand up to cancer phase $\mathrm{lb}$ study of pan-phosphoinositide-3-kinase inhibitor buparlisib with letrozole in estrogen receptor-positive/human epidermal growth factor receptor 2-negative metastatic breast cancer. J Clin Oncol 2014; 32: 1202-1209.

65. Shi R, Li W, Zhang X, Zhang Y, Peng H, Xie $\mathrm{Y}$ et al. A novel indirubin derivative PHII-7 potentiates adriamycin cytotoxicity via inhibiting P-glycoprotein expression in human breast cancer MCF-7/ADR cells. Eur J Pharmacol 2011; 669: 38-44.

66. Zhou Y, Hu Y, Yang M, Jat P, Li K, Lombardo $Y$ et al. The miR-106b 25 cluster promotes bypass of doxorubicin-induced senescence and increase in motility and invasion by targeting the E-cadherin transcriptional activator EP300. Cell Death Differ 2014; 21: 462-474.

67. Zhao JJ, Gjoerup OV, Subramanian RR, Cheng Y, Chen W, Roberts TM et al. Human mammary epithelial cell transformation through the activation of phosphatidylinositol 3-kinase. Cancer Cell 2003; 3: 483-495.

68. Hu Y, Li S, Yang M, Yan C, Fan D, Zhou Y et al. Sorcin silencing inhibits epithelial-tomesenchymal transition and suppresses breast cancer metastasis in vivo. Breast Cancer Res Treat 2014; 143: 287-299.

69. Hu Y, Cheng X, Li S, Zhou Y, Wang J, Cheng T et al. Inhibition of sorcin reverses multidrug resistance of K562/A02 cells and MCF-7/A02 cells via regulating apoptosis-related proteins. Cancer Chemother Pharmacol 2013: 72: 789-798.

(i) Cell Death and Disease is an open-access journal published by Nature Publishing Group. This work is licensed under a Creative Commons Attribution 4.0 International License. The images or other third party material in this article are included in the article's Creative Commons license, unless indicated otherwise in the credit line; if the material is not included under the Creative Commons license, users will need to obtain permission from the license holder to reproduce the material. To view a copy of this license, visit http://creativecommons.org/licenses/by/4.0/ 